\title{
Percepção dos perigos ambientais urbanos e os efeitos de lugar na relação população-ambiente*
}

\author{
Eduardo Marandola Jr.** \\ Francine Modesto***
}

\begin{abstract}
Os estudos ambientais enfrentam, desde seu advento, o fantasma da falácia ecológica. Especialmente no âmbito das ciências humanas, sempre houve uma atenção redobrada em relação a qualquer forma de determinismo geográfico ou interpretação que submetesse a compreensão da sociedade à lógica da natureza. Nos estudos de População e Ambiente ( $P$-A), esta preocupação esteve sempre presente, não sendo raro o debate sobre a falácia ecológica, seus riscos e a busca por formas de eliminá-la do escopo das análises. No entanto, com o interesse redobrado das ciências humanas pelo espaço nas últimas décadas, a importância da espacialidade e a contínua incorporação de sua dimensão nas análises renovam esta preocupação, agora em um novo contexto sociocultural. A ideia de efeitos de lugar ganha relevo à medida que se reconhece, na contramão da mundialização, o reforço de fatores regionais e locais na determinação e mediação de problemáticas ambientais que afetam populações e lugares de maneira específica, e não de forma indiscriminada pelo espaço. Nesse contexto, o debate metodológico precisa dar atenção à forma como o espaço entra na equação $P$-A, sem desconsiderar o histórico dos debates ou os novos arranjos socioespaciais contemporâneos. Estas questões apresentaram-se como relevantes na pesquisa desenvolvida sobre a percepção dos perigos e a vulnerabilidade nas Regiões Metropolitanas de Campinas e da Baixada Santista, no Estado de São Paulo. Utilizando dados de uma pesquisa domiciliar desenvolvida em 2007 (Projeto Vulnerabilidade), procuramos ir além das variáveis que costumeiramente nos ajudam a pensar as questões referentes à situação de vida (renda, escolaridade, ciclo vital), tentando entendê-las em escalas espaciais diferenciadas, incorporando os efeitos de lugar como fundamentais para compreender a percepção dos perigos urbanos na relação populaçãoespaço-ambiente.
\end{abstract}

Palavras-chave: Riscos. Espaço. Migração. Metodologia. População. Ambiente.

\footnotetext{
* Uma primeira versão deste artigo foi apresentada na sessão temática "Aspectos teóricos e metodológicos no estudo da relação população, espaço e ambiente", do Grupo de Trabalho População, Espaço e Ambiente, durante o XVII Encontro Nacional de Estudos Populacionais, Abep, realizado em Caxambu (MG), em setembro de 2010.

** Geógrafo, Faculdade de Ciências Aplicadas, Universidade Estadual de Campinas - FCA/Unicamp.

*** Socióloga, mestre e doutoranda em Demografia pela Universidade Estadual de Campinas (IFCH/Unicamp); Núcleo de Estudos de População (Nepo/Unicamp). Bolsista CNPq.
} 


\section{População e ambiente: desafios metodológicos}

Enquanto campo de pesquisa consolidado, os estudos em População e Ambiente $(\mathrm{P}-\mathrm{A})$ têm à sua frente o desafio de avançar em metodologias de análise para aprofundar a compreensão da relação dos grupos populacionais e seus ambientes. Este desafio tem várias facetas que se apresentam aos estudiosos da área.

Entre as dificuldades históricas do campo está a necessidade de incorporação da dimensão espacial às análises. Embora isso seja amplamente reconhecido e até reivindicado enquanto essencial (MARTINE, 2007), os caminhos para tal intento continuam sinuosos e imprecisos. Na visão de Lutz, Prskawetz e Sanderson (2002), um dos pontos mais importantes para a consolidação do campo de P-A é conseguir, metodologicamente, construir uma abordagem eminentemente relacional, que não enfatize a flecha no sentido $P \rightarrow A$ nem $A \rightarrow P$. A saída para este dilema é conseguir considerar de forma equilibrada os aspectos do polo Ambiente em suas características próprias. É aí que a dimensão espacial aparece como sugestão de solução.

Historicamente, a questão do espaço tem sido trabalhada a partir do componente da distribuição espacial da população, reconhecidamente a questão central dos estudos (HOGAN, 2000; MARTINE, 2001). Em termos teórico-metodológicos, no entanto, a incorporação do espaço tem sido difusa, partindo de matrizes de outras áreas (especialmente a ecologia humana e a produção do espaço) e não de uma discussão propriamente demográfica (MARANDOLA JR.; HOGAN, 2007a). No entanto, se tematicamente o espaço já faz parte do escopo das análises (foi até mesmo incluído no nome do Grupo de Trabalho da Associação Brasileira de Estudos Populacionais, a partir de 2006), metodologicamente ele ainda carece de uma incorporação mais efetiva no conjunto dos estudos em P-A.

Há vários motivos para esta permanente dificuldade, que não diferem dos motivos de outras áreas em incorporar as questões propriamente espaciais dos processos em questão. Entre eles, a falácia ecológica (atribuir características individuais tendo como base observações de dados agregados a partir de esferas de grupo ou de recortes espaciais) é um fantasma que acompanha todo o desenvolvimento teórico e metodológico dos estudos de P-A, servindo de alerta constante para os pesquisadores. Este fantasma teve sempre um papel ambíguo de ameaça e de patrulhamento, servindo como fonte de desconfiança para aqueles que tratavam a dimensão ideologicamente, procurando descaracterizar ou desqualificar questões ambientais que tinham raízes ou eram produzidas por iniquidades sociais (MARTINE, 1993).

No entanto, mesmo fora do contexto dos estudos de P-A, a Demografia tem avançado e procurado incorporar a dimensão espacial. Paul Voss (2007) afirma que o espaço está presente na Demografia desde sua gestação inicial, mas que nos últimos anos adquiriu novo papel. O autor defende a demografia espacial como campo específico, por tratar os fenômenos demográficos numa perspectiva eminentemente espacial. Este olhar não se restringe às técnicas modernas de geoprocessamento, estando ligado direta e indiretamente a uma perspectiva metodológica e epistemológica de considerar a dimensão espacial dos fenômenos.

Um dos principais embates que trazem a importância de um olhar espacial à Demografia são os cortes escalares macro e micro. Os estudos demográficos vêm utilizando recortes espaciais, mas não têm incorporado propriamente uma perspectiva metodológica e analítica das implicações escalares destes recortes. Voss (2007) defende a necessidade de incorporar as variáveis ecológicas e os efeitos de vizinhança na análise demográfica em todas as escalas, o que permitiria estudos de perfis escalares do tipo down ou up-scales. Tais análises, complementares, são muito presentes nos estudos de P-A, sendo uma das principais estratégias de aproximação de processos de organização regional ou nacional com processos específicos de uso e ocupação do solo (BARBIERI, 2007; D'ANTONA; CAK; VANWEY, 2007). 
Barbara Entwisle (2007), por outro lado, procura "colocar as pessoas no lugar", ao avaliar os estudos ecológicos em Demografia, especialmente aqueles ligados às análises de vizinhança e de saúde. O espaço é considerado metodologicamente nas análises a partir dos efeitos ou impactos de vizinhança, levando-se em conta fatores como proximidade, relações topológicas e recursos disponíveis na comunidade como variáveis ecológicas fundamentais para entender as questões de saúde. Esses efeitos de vizinhança, ou de forma mais ampla efeitos de lugar (place effects), são estudados nas Ciências Sociais, na Psicologia, nas Ciências da Saúde e até nos estudos de políticas públicas e gestão do território.

Esses estudos buscam uma alternativa para a falácia ecológica que não implica fugir dos elementos espaciais e ambientais. Sua estratégia é diminuir a escala e investigar de maneira mais detida as múltiplas influências e formas de envolvimento das pessoas com o lugar, encontrando aí as variáveis e nuances que ligam as pessoas aos lugares. A questão é qualificar esse envolvimento para poder reconhecer o que interfere, nesta escala, na relação sociedade-natureza.

Macintyre, Ellaway e Cummins (2002, p.125) afirmam que os efeitos de lugar são uma categoria residual, uma caixa preta dos estudos a respeito da influência do ambiente sobre a população. Para avançar neste sentido, eles adotaram que "a distinção entre 'composição' e 'contexto' pode ser mais aparente do que real, e as características tanto de infraestrutura material quanto do funcionamento social do coletivo podem influenciar a saúde" (tradução nossa). Em termos dos estudos demográficos, esta distinção permite ver de forma simultânea e articulada os elementos estruturais do lugar (físicos, simbólicos ou relacionais) e os componentes próprios da população: seus atributos, estrutura e composição.
Esse se mostra um caminho promissor para os estudos de P-A. Os efeitos de lugar envolvem uma ampla gama de questões que permitem associar as variáveis ecológicas às consequências e condicionantes de problemas ambientais, como riscos e perigos, poluição, contaminação, além de revelarem de forma mais precisa os fatores que interferem na forma como as populações reagem e dão resposta a tais situações de estresse ambiental (vulnerabilidade).

Por outro lado, os efeitos de lugar são importantes para compreender a mediação escalar do lugar, abrindo a possibilidade de se pensar o papel das escalas nas atitudes e percepções das pessoas diante de perigos específicos, ou da situação ambiental de forma mais geral.

Estas questões têm sido abordadas tradicionalmente pelas mediações sociais e culturais mais evidentes, tais como renda e escolaridade, bem como origens religiosas ou culturais. No entanto, com a fluidez contemporânea e a velocidade das comunicações e da mobilidade, as dinâmicas socioculturais têm se generalizado mais intensamente. Este processo, ao invés de enfraquecer as mediações das escalas menores, tem reforçado a importância da heterogeneidade, enfatizando a questão local como uma das escalas de mediação das pessoas com o mundo (BOURDIN, 2001). Neste sentido, as percepções que as pessoas têm das questões ambientais expressam de forma candente os efeitos do lugar e seu papel na relação P-A, enquanto dimensão espacial fundamental da problemática.

Estes são temas que têm sido perseguidos nos trabalhos desenvolvidos no Núcleo de Estudos de População, pela equipe ligada à linha População e Ambiente e ao Projeto Vulnerabilidade. ${ }^{1}$ Neste contexto, as questões do lugar são pensadas em relação aos perigos e à mobilidade, a partir

\footnotetext{
1 Projeto realizado de 2003 a 2008: "Dinâmica intra-metropolitana e vulnerabilidade sociodemográfica nas metrópoles do interior paulista: Campinas e Santos" (http://www.nepo.unicamp.br/vulnerabilidade), com um espólio de dados e discussões que ainda estão sendo discutidos em outros projetos, tais como "Mobilidade populacional, ciclo vital e vulnerabilidade sociodemográfica em regiões metropolitanas: abordagens geográficas qualitativas" (Prodoc/Capes), em desenvolvimento desde 2008.
} 
da abordagem da vulnerabilidade do lugar (MARANDOLA JR.; HOGAN, 2009). Utilizando basicamente uma abordagem qualitativa, de orientação fenomenológica, a equipe tem avançado no sentido de compreender os elementos componentes da experiência urbana que interferem nas atitudes e na forma como pessoas, grupos e lugares reagem diante de certos perigos. A abordagem estabelece a relação entre as escalas do bairro, da cidade e da região, tentando acompanhar os perigos e o desenho da vulnerabilidade a partir de um olhar micro (lugar) e meso (região) da experiência.

Um dos desafios desta perspectiva é conseguir transgredir as escalas e as temporalidades, identificando elementos essenciais que permitam pensar os processos enquanto fenômenos, e não apenas como excepcionalidade de um caso. Uma das estratégias neste sentido foi a inclusão, no levantamento amostral por domicílio realizado pelo Projeto Vulnerabilidade, em 2007, no módulo sobre as características do domicílio e de seu entorno, de quesitos que exploram a percepção dos perigos em diferentes escalas. Embora com limitações inerentes à sua própria característica, tal levantamento permite discutir aspectos relevantes do papel dos efeitos do lugar em problemáticas de P-A, especialmente ligados aos perigos ambientais urbanos.

O objetivo deste artigo é iniciar esta discussão, procurando refletir sobre as implicações desta pesquisa para uma reflexão metodológica que incorpore os efeitos de lugar nos estudos de P-A enquanto estratégia de apreensão da dimensão espacial e transescalar dos fenômenos demográficos.

Para isso, é necessário pensar as variáveis pertinentes do lugar para os estudos de P-A e refletir sua aderência ao desenho amostral e teórico-metodológico da fonte dos dados.

\section{O lugar e seus efeitos}

Lugar é uma essência ou categoria espacial que implica proximidade. Embora alguns o tomem como um conceito multiescalar (TUAN, 1983), é na escala da experiência corpórea que ele tem sua maior força e seus significados são mais densos e abundantes (RELPH, 1976).

Os estudos interdisciplinares sobre o lugar, embora partam deste entendimento básico fundamentado nos geógrafos humanistas dos anos 1970, procuram sistematizar e compreender as formas como o lugar é constituído, bem como suas influências nos âmbitos social e ambiental. Da Geografia herdaram um olhar específico sobre a centralidade da experiência e da escala próxima para a construção dos lugares, mas acrescentaram uma gama de elementos sistemáticos para medir o que passou a ser chamado de efeitos de lugar.

A abordagem psicométrica, por exemplo, trabalha com uma tríade de componentes para medir a relação das pessoas com o lugar: envolvimento com o lugar (place attachment), identidade com o lugar (place identity) e dependência do lugar (place dependence), os quais envolvem diferentes atitudes, respectivamente: afetação, cognição e elementos conotativos (KYLE et al., 2004). Envolvimento com o lugar corresponde aos laços emocionais que ligam a pessoa a um lugar; identidade com o lugar é o grau de características do lugar que refletem a pessoa, enquanto a dependência do lugar refere-se ao grau de facilidades comparativas oferecidas pelo lugar.

Estes conceitos, embora muito empregados por uma ampla bibliografia (ALTMAN; LOW, 1992), possuem uma carência teórica básica: "As relações teóricas entre os construtos de ligação com o lugar, no entanto, não são consistentemente empregadas" (NIELSEN-PINCUS, 2010, p. 1, tradução nossa). Falta um olhar mais geral que esteja "conectado com a relação entre este conceito e outros que façam referência equitativa aos laços que estabelecemos com o nosso meio." (HERNÁNDEZ et al., 2007, p. 311, tradução nossa).

Hernández et al. (2007) procuram ampliar as possibilidades analíticas destes conceitos, estudando o envolvimento com o lugar entre nativos e não nativos em três ambientes diferentes: bairro, cidade e ilha. Os resultados apontam para o maior envolvimento dos nativos, que pelo tempo de experiência no/com o lugar possuem maior 
identificação e laços afetivos com ele. Não é possível, argumentam os autores, determinar um mínimo de tempo de envolvimento, mas a linha é ascendente em relação ao tempo de residência.

A pesquisa aponta ainda que o envolvimento e a identidade com o bairro são menos fortes do que com a cidade e a ilha, contrariando a tradição de estudos que têm dado maior ênfase aos bairros e às comunidades. Embora reconheçam a necessidade de mais estudos para apoiar esta tendência, os autores atribuem o resultado das relações simbólicas mais fortes, no caso da cidade e da ilha, a uma história compartilhada e com limites mais definidos do que o bairro. Por outro lado, pode-se pensar que o bairro contemporâneo é a primeira célula espacial a sofrer com os processos de fluidez e desagregação da identidade e do mundo do trabalho (BAUMAN, 2003; 2007).

A dimensão do pertencimento é uma das mais complexas a se abordar. A posição do ego no discurso expõe a forma de se colocar no mundo e de perceber o próprio ambiente. O lugar "pertence a mim" ou "faz parte de mim"? Nesta, a posição do ego está expressa na natureza do envolvimento, identidade e dependência com/no lugar (KYLE et al., 2004).

No caso do "pertence a mim", a relação com o lugar é a de posse. O ambiente é recurso e ativo que são movimentados e transformados de acordo com as necessidades, vontades e desejos. Já o entendimento "faz parte de mim" implica um envolvimento inerente homem-meio, uma relação de cumplicidade que envolve o cuidado e a identidade. No primeiro há a ênfase da dependência, enquanto no segundo destacam-se a identidade e o envolvimento.

É para aprofundar esta discussão que o sentido geográfico de lugar, associado a uma leitura fenomenológica, pode contribuir. Lugar é a existência, sem dissociação do ego: uma cumplicidade visceral homemterra que tem sua manifestação máxima no lugar, expressão da própria ontologia da espacialidade, ou como prefere Dardel (1952), da geograficidade.

Lugar assim entendido é construído na entridade (betweenness), uma característica própria de estar-com por estar-entre, edificado entre a objetividade e a subjetividade, ou seja, na intersubjetividade das experiências (ENTRIKIN, 1991). No lugar estão o enraizamento e o envolvimento e, em última análise, as possibilidades de ligação elementar com as escalas superiores. Não é, portanto, uma leitura essencialista. Antes, é uma perspectiva relacional e contextual.

No entanto, os lugares não são homogêneos, e nosso envolvimento com eles varia muito em intensidade, característica e tempo de experiência. Relph (1976) foi um dos primeiros a sistematizar estas possibilidades de envolvimento, adotando dois conceitos fundamentais: interioridade (insiderness), ou senso de pertencimento, e exterioridade (outsiderness), senso de não pertencimento. Para o autor, este envolvimento diferenciado com lugares estava ligado às características próprias deles, bem como à natureza da relação da pessoa com ele. Esta relação entre interioridade e exterioridade é a base para a identidade do lugar, estabelecendo um gradiente de relacionamento que dilui a tradicional polarização insider-outsider (de dentro e de fora). Relph propõe entender os lugares no âmbito de suas características físicas (forma), atividades e significados, tentando compreender a experiência na intersubjetividade.

Os lugares, no entanto, não são apenas externos, são internos também: as pessoas carregam em seus corpos os lugares. É por isso que os estudos de lugar precisam abarcar os dois polos da relação P-A: o lugar tem características próprias (os efeitos de dependência e de identificação), mas as pessoas precisam se identificar e se envolver com ele, ou seja, precisam ter nelas mesmas sentimentos e memórias que estabeleçam ligações com o lugar (LOWENTHAL, 1975; LEWICKA, 2008; 2010).

Em termos demográficos, é essencial pensar que tipo de experiência demográfica as pessoas carregam em seus corpos. Ciclo vital, gênero, estrutura familiar, morbidades, condição migratória não costumam ser considerados em sua dimensão espacial (salvo o último), mas são essenciais para a compreensão do próprio lugar e, em contrapartida, também da forma como aquela 
comunidade se vê e se envolve com ele. Nielsen-Pincus et al. (2010) investigaram o papel de três aspectos sociodemográficos na composição dos laços com o lugar: pertencimento de grupo (residentes locais vs. proprietários não moradores), tempo de residência e sazonalidade da residência, entendendo estas variáveis como reveladoras do envolvimento com o lugar e mostrando como o tempo de experiência tanto interfere na forma e intensidade da identidade, dependência e envolvimento com o lugar, quanto contribui para fortalecer os laços de confiança e de proteção do próprio lugar.

A relação P-A se dá justamente nesta intersubjetividade singular: grupos demográficos, que possuem e carregam suas trajetórias, coletividades e territorialidades, tentando identificar-se e envolver-se com outras trajetórias, coletividades e territorialidades. Neste processo, constituem lugares ao mesmo tempo em que são constituídos por eles.

\section{Perigos urbanos e a percepção do ambiente}

Acompanhar estes níveis de envolvimento, pertencimento e dependência, no entanto, não é uma tarefa simples. Duas estratégias têm sido mais utilizadas para tentar abarcar estes processos: as pesquisas qualitativas, com imersão e envolvimento do pesquisador; e os levantamentos de percepção e atitudes ambientais. A primeira permite a discussão mais aprofundada dos processos e fenômenos constituintes do lugar e das circunstâncias e possibilidades diferenciadas de envolvimento. Estas pesquisas lançam luz sobre características particulares, provocando a formulação de entendimentos que projetam teorias compreensivas dos fenômenos. A segunda pode servir tanto de antena para fenômenos ou aspectos significativos que são mais gerais (aparecem na heterogeneidade), quanto para avaliar a amplitude de compreensões provenientes dos estudos de imersão. Em vista disso, as duas estratégias são complementares e se retroalimentam.

Temos trabalhado com pesquisas específicas, procurando a compreensão fenomênica do lugar e sua dinâmica própria (MARANDOLA JR., 2008a; MARANDOLA JR.; HOGAN, 2009). Estes estudos permitiram avançar na reflexão sobre a percepção dos perigos urbanos e os componentes da vulnerabilidade, bem como a dimensão do lugar nos processos de P-A. Por outro lado, estas pesquisas fundamentaram a elaboração de quesitos para o questionário do levantamento domiciliar amostral realizado pelo Projeto Vulnerabilidade, em 2007, fornecendo assim dados mais abrangentes sobre os efeitos de lugar na percepção dos perigos urbanos em contextos de elevada urbanização.

Três questões centrais nortearam a elaboração das questões, a partir destas experiências de pesquisa:

- os perigos compreendem os fenômenos concretos que causam dano e, portanto, são eles, e não os riscos, que devem ser questionados. Os perigos constituem a materialidade que aparece na experiência das pessoas, e por isso precisamos primeiro entender a percepção deles, para depois pensarmos a dimensão dos riscos (a probabilidade de eles ocorrerem) (MARANDOLA JR.; HOGAN, 2007b; 2009);

- a percepção dos perigos está diretamente ligada à posição na cidade e na região, sendo esta posição uma expressão dos círculos sociais e culturais em que a pessoa está exposta e potencialmente inserida, bem como das restrições e potencialidades espaciais que mediam sua visão dos perigos e do próprio ambiente (DE PAULA; MARANDOLA JR.; HOGAN, 2007; MARANDOLA JR., 2008b);

- a condição de migrante é um viés fundamental na experiência espacial que interfere diretamente na forma como a pessoa vive e percebe o ambiente e o urbano. Ser migrante ou não é essencial no enfrentamento e percepção dos perigos urbanos (MARANDOLA JR., 2008b; 2008c). 
A percepção é extremamente sensível para captar as consequências do envolvimento com o lugar e suas nuances, porque está no nível mais elementar de relacionamento sensorial do corpo com o mundo, desde que se atente para as mediações (PINHEIRO, 1997; 2006). A percepção tem sido utilizada há muito tempo para conhecer e investigar os sentidos e as identidades dos lugares nos estudos urbanos e ambientais, justamente por apresentar a apreensão do mundo visual de forma imediata, sem mediações (GIBSON, 1974; OLIVEIRA, 1977; LYNCH, 2003).

A percepção, diferente de como é trabalhada por alguns, é parte constituinte do próprio fenômeno, ou seja, seu estudo é um caminho que nos permite tentar compreender o porquê de as pessoas terem determinada percepção que talvez não seja a mesma verificada pelo estudo técnico. A percepção é intuitiva, imediata, e é por isso que, com relação à maioria dos perigos, as pessoas não passam da sua percepção, pois não chegam a refletir ou elaborá-los enquanto tal. Os perigos são constituintes da história de vida das pessoas e da própria forma como elas se colocam nas cidades, como elas constroem suas identidades, mas nem sempre se tornam conscientes.

A percepção dos perigos é o primeiro passo porque estes são tangíveis, diferentemente dos riscos, que necessitam de uma elaboração cognitiva para sua apreensão. Os perigos podem ser perguntados de forma mais direta, enquanto os riscos requerem um trabalho maior para a acurácia no questionário. Neste sentido, as perguntas sobre perigos específicos (áreas contaminadas, trânsito, poluição, etc.) são mais adequadas para um questionário grande cujo objetivo era maior do que este módulo de questões.

Há uma ampla bibliografia sobre percepção de riscos, com longa tradição de estudos e de estratégias metodológicas, mostrando que muitos fatores interferem na percepção, desde a renda, a escolaridade, os círculos culturais e religiosos e o lugar, até os ativos e as estruturas materiais disponíveis para as pessoas enfrentarem os perigos (KATES, 1967; DOUGLAS, 1985;
1987; LUPTON, 1999; SLOVIC, 2000). Medos, incertezas e as características próprias dos eventos, como a distinção entre perigos naturais, sociais e tecnológicos, também são importantes para perceber as diferenças na percepção (SAARINEN, 1966; LUHMANN, 1993; WILDAVSKY; DAKE, 1994). Nos últimos anos cresceu uma tendência de ler a percepção dos perigos como manifestação dos novos cenários globais de comunicação, investigando-se o papel dos diferentes atores na comunicação e na construção social do próprio risco, além, é claro, de uma preocupação em compreender os processos de estigmatização e amplificação social do risco (CASTIEL, 2002; KASPERSON; KASPERSON, 2005).

Todos estes desenvolvimentos ajudaram a compreender melhor a forma como o risco é compreendido e construído socialmente em contextos culturais distintos. No entanto, os efeitos de lugar nesta percepção não têm recebido a mesma atenção. A influência da situação e posição espacial e os processos de identificação, dependência e envolvimento com o lugar não têm sido considerados com a mesma frequência que os processos socioculturais na delimitação dos fatores que interferem na percepção dos riscos e perigos. É justamente nesta seara que elaboramos as questões e procuramos indícios para a discussão.

Os elementos espaciais que foram incluídos nas questões, que permitem discutir os efeitos de lugar foram:

- Escala dos perigos - diz respeito às perguntas da percepção dos perigos em três escalas: entorno da casa (bairro), cidade e região. Este quesito possibilita compreender as questões de proximidade e distância, centrais para discussão da percepção, pois os perigos são percebidos de forma muito diferente nestas escalas;

- Posição - refere-se à situação de moradia na região metropolitana (RM). O desenho amostral não permite a representatividade por municípios, mas sim por sede da RM e os demais municípios do entorno, o que oferece uma situação espacial, 
embora heterogênea, com especificidades significativas para entender o posicionamento em relação à centralidade e às estruturas espaciais e simbólicas diferenciais. Morar na sede e no seu entorno implica condições e especificidades espaciais que possibilitam aventar questões referentes à percepção e ao seu viés topológico;

- Condição migratória: esta é atribuída a partir do quesito tempo de residência. Trata-se de elemento muito importante porque diz respeito tanto à experiência espacial que a pessoa tem da cidade e da RM - mais tempo, mais experiência -, que lhe permite conhecer perigos e sistemas de proteção, quanto às experiências espaciais anteriores que a pessoa traz para o novo lugar, modificandoo também. Os migrantes carregam seus lugares e nesse processo são transformados ao mesmo tempo em que transformam.

Os três elementos podem ser balizados pelas respostas aos quesitos sobre mobilidade (cotidiana e pendular), bem como pelos dados da migração intraurbana, que permitem identificar alguns traços da experiência espacial das pessoas na região e na cidade, o que interfere sem dúvida na sua percepção e na forma como se inserem social e espacialmente.

O questionário foi aplicado em 1.823 domicílios entre os 19 municípios da Região Metropolitana de Campinas (RMC) e em 1.595 domicílios dos nove municípios da Região Metropolitana da Baixada Santista (RMBS) - as duas RMs do interior do Estado de São Paulo -, no segundo semestre de 2007. Seu desenho amostral foi feito a partir de Zonas de Vulnerabilidade (ZVs), que foram compostas por meio dos dados do Censo 2000, sem representação espacial, mas permitindo uma análise domiciliar (CUNHA et al., 2006).

Com um questionário organizado em vários módulos, as questões de percepção dos perigos ficaram no primeiro, aparecendo na sequência das questões referentes às características do domicílio e do bairro. Isso facilitou as respostas, pois as pessoas já estavam, no momento das perguntas, com a atenção voltada para o entorno da casa e suas condições, além de estar no início do questionário, sem terem sido mencionados os demais temas (família, renda, trabalho, saúde, educação, etc.) (CUNHA, 2009a; 2009b).

As questões sobre percepção eram semiabertas, com categorias predefinidas, nas quais o entrevistador classificava as respostas. Quando a resposta era espontaneamente múltipla, a orientação era que se perguntasse ao entrevistado qual daquelas era a mais relevante para ele. As categorias foram definidas tanto pelos pré-testes realizados na montagem geral do questionário, quanto pelas pesquisas empíricas em bairros de Campinas que a equipe vinha realizando ao longo do Projeto.

Aplicado apenas a domicílios urbanos, o questionário foi prioritariamente respondido por mulheres, responsáveis pelo domicílio ou esposas dos responsáveis. Na inexistência delas ou na sua ausência irremediável, o questionário foi respondido por homens responsáveis pelo domicílio. O motivo de tal escolha está associado à complexidade das perguntas e ao entendimento de que as mulheres teriam melhores condições de responder aos sete módulos do questionário devido ao seu maior envolvimento com os membros do domicílio.

A amostra envolve cerca de $70 \%$ de respondentes mulheres (Tabela 1). Embora não seja possível indicar estatisticamente um viés de gênero claro em relação à percepção dos perigos ambientais (os dados não diferem entre homens e mulheres), é importante estar atento para a quantidade das mulheres respondentes, bem como ao direcionamento do próprio questionário, que foi elaborado tendo-se em mente que teríamos mulheres como informantes.

Castro e Abramovay (2005) apontam para a importância de avançar na compreensão da perspectiva de gênero ao se pensar o ambiente, já que esta permite entender o papel de homens e mulheres nas organizações, no que se refere às questões contemporâneas. A bibliografia sobre percepção de risco está atenta ao viés de gênero e há 
TABELA 1

Respondentes do questionário, por sexo

Regióes Metropolitanas de Campinas e da Baixada Santista - 2007

\begin{tabular}{|c|c|c|c|c|}
\hline \multirow{2}{*}{ Sexo } & \multicolumn{2}{|c|}{ RMC } & \multicolumn{2}{|c|}{ RMBS } \\
\hline & N. abs. & $\%$ & N. abs. & $\%$ \\
\hline Homens & 554 & 30,39 & 460 & 28,84 \\
\hline Mulheres & 1.269 & 69,61 & 1.135 & 71,16 \\
\hline Total & 1.823 & 100,0 & 1.595 & 100,0 \\
\hline
\end{tabular}

Fonte: Pesquisa domiciliar do Projeto Vulnerabilidade Fapesp/CNPq. Tabulações especiais, Nepo/Unicamp (2007).

estudos que indicam a significativa diferença da percepção entre homens e mulheres em relação tanto aos tipos de risco quanto à própria percepção do ambiente. Segundo Gustafson (1998), embora sociólogos e antropólogos classifiquem que os riscos são social e culturalmente construídos, estudos da psicologia revelam, segundo o autor, que existe uma dimensão subjetiva na percepção dos indivíduos, pois a percepção de risco não apenas reflete a exposição a ele, mas também é influenciada pela experiência individual e pelas construções coletivas. Dessa forma, homens e mulheres não só percebem os mesmos riscos de maneiras diferentes, como também percebem riscos diferentes.

Existem algumas hipóteses que tentam explicar as diferenças na percepção do risco entre homens e mulheres, tais como condições biológicas, experiência de algum risco e diferenças sociais (FLYNN et al. 1994). Entre as causas sociais, pesquisas qualitativas têm mostrado que a atenção das mulheres com a casa e a família se reflete em sua percepção dos riscos, tornando-as preocupadas com ameaças à sua família e a outras pessoas com quem tenham relações estreitas, bem como com relação à sua casa, como mostram Jakobsen e Karlsson (apud GUSTAFSON, 1998). Frequentemente são mencionados riscos de acidentes, riscos de saúde e de morte. A mesma pesquisa mostra que as preocupações dos homens estão relacionadas em maior grau com a vida profissional, como, por exemplo, risco de ficar desempregado e problemas econômicos. Porém, isso não indica que as diferenças de gênero nas percepções de risco estão ligadas às atividades e aos papéis sociais de homens e mulheres, mas sim às desiguais relações de poder que ambos exercem nos diferentes contextos sociais.

Um componente importante da percepção do risco é a percepção do perigo, o evento concreto, o que está relacionado diretamente à experiência. Algumas pesquisas revelam que os homens tendem a manifestar níveis mais baixos de preocupação quando questionados sobre perigos ambientais. Por se preocuparem menos, sua atenção e consequentemente sua percepção dos riscos também são menores do que as das mulheres (FLYNN et al., 1994; RIECHARD et al., 1998; FINUCANE et al., 2000; HENWOOD, 2008).

Mas essa perspectiva não é uma unanimidade. Greenberg et al. (1995) rebatem a ideia de percepções ambientais diferenciadas entre os sexos. Os autores defendem que homens e mulheres que residem em uma mesma vizinhança e que vivenciam múltiplos perigos demonstram preocupações parecidas sobre as condições do ambiente local.

No caso dos dados da pesquisa, isso pode ter ressonância na não diferenciação estatística entre as respostas de homens e mulheres. Por outro lado, não é demais lembrar que o desenho amostral não foi espacial, baseando-se em Zonas de Vulnerabilidade (ZVs), o que também não sustenta um viés espacial nas respostas. As ZVs foram compostas com base em características apreendidas de quesitos do Censo 2000 que representassem o capital social, humano e físico, o que deu ênfase para a escolaridade, a renda e outros aspectos sociodemográficos (CUNHA et al., 2006). Este é outro viés importante na amostragem.

Trabalhamos com os dados/valores reais, sem expansão da amostra, para obter 
uma precisão mais clara dos dados. Foram utilizados dois conjuntos de dados que mediram a percepção, sempre cortados por duas categorias: posição e condição migratória. Cada conjunto de dados permite ver, a partir destas categorias, indícios dos efeitos de lugar agindo na diferenciação das respostas e na própria interpretação dos dados.

O primeiro foi apreendido pelos quesitos 52 a 66 do questionário, que envolvem questões sobre as vantagens e os perigos de viver no bairro, na cidade e na RM. Estas perguntas objetivavam identificar a influência da experiência direta dos perigos para a percepção, assim como possíveis ajudas e correlações entre os conjuntos de perigos. A violência foi indagada de maneira separada para poder abrir espaço para outros perigos serem mencionados.

O segundo conjunto refere-se aos quesitos 67 a 82 do questionário, que listam uma série de perigos, os quais os informantes devem classificar como muito grave, grave, pouco grave, nada grave e não sabe. Estas questões foram direcionadas para o entorno da casa, contendo, portanto, uma escala próxima referente ao próprio lugar.

Assim, levando-se em conta este desenho amostral, as características da composição do questionário e as questões levantadas por nossas pesquisas no campo da vulnerabilidade do lugar, propomos discutir dois temas centrais que perseguimos a partir dos dados da pesquisa: qual o papel do lugar na percepção dos perigos ambientais urbanos? Qual o impacto do tempo de residência e do envolvimento com o lugar na relação P-A? Esperamos que estas questões subsidiem uma reflexão metodológica sobre o papel dos efeitos de lugar nos estudos de P-A.

Discutem-se os dados a partir das categorias de análise, incluindo aí a discussão por escalas, com o intuito de que, com isso, seja possível ressaltar seu papel na forma como a percepção dos perigos se revela.

\section{Posição: sede e entorno}

Com aproximadamente 2,7 e 1,7 miIhões de habitantes, a RMC e a RMBS, respectivamente, são áreas de concentração de fluxos, de densa urbanização e de concentração de serviços. A mobilidade intrarregional e as migrações internas são significativas do conjunto de sua dinâmica populacional, apresentando um elevado dinamismo econômico e cultural (JAKOB, 2002; PIRES, 2007; MARANDOLA JR., 2008a).

Em termos ambientais e de sítio, porém, as duas RMs não poderiam ser mais diferentes. A RMC está na transição entre o Planalto Atlântico (onde está a Região Metropolitana de São Paulo) e a Depressão Periférica Paulista, de terrenos sedimentares aplainados, por onde se consolidaram uma ampla conurbação e um processo de dispersão. Este último ocorre em mancha em quase todas as direções (exceto justamente o leste, onde dominam os relevos do Planalto), seguindo os eixos rodoviários de grande porte, denominados por Caiado e Pires (2006) de eixos de desenvolvimento (Mapa 1).

Apesar da concentração da sede, inerente aos processos de metropolização, a RMC possui uma relativa desconcentração oriunda da sua própria formação a partir dos anos 1970 (PIRES, 2007). Há cinco cidades com mais de 150 mil habitantes (três delas com mais de 200 mil), sendo outras cinco com população superior a 50 mil pessoas (estando duas no limiar dos 100 mil). Estas cidades apresentam significativa atividade comercial e de serviços, especialmente desde os anos 1990, tendo uma relação com a sede mais independente do que os modelos de metropolização da era industrial produziram. As trocas populacionais e a pendularidade não estão apenas direcionadas para a sede, apresentando interações espaciais significativas entre os municípios do entorno (MARANDOLA JR., 2008a).

Em vista disso, em vez de uma mancha mais densa em torno do centro metropolitano, temos um padrão rizomático de desenvolvimento da mancha urbano-metropolitana, capilarizada pelas grandes rodovias e pelos principais corredores viários. Esse padrão de construção, que desde os anos 1970 elegeu a região como o local da produção do espaço urbano, privilegiou as localizações mais conectadas à densa 


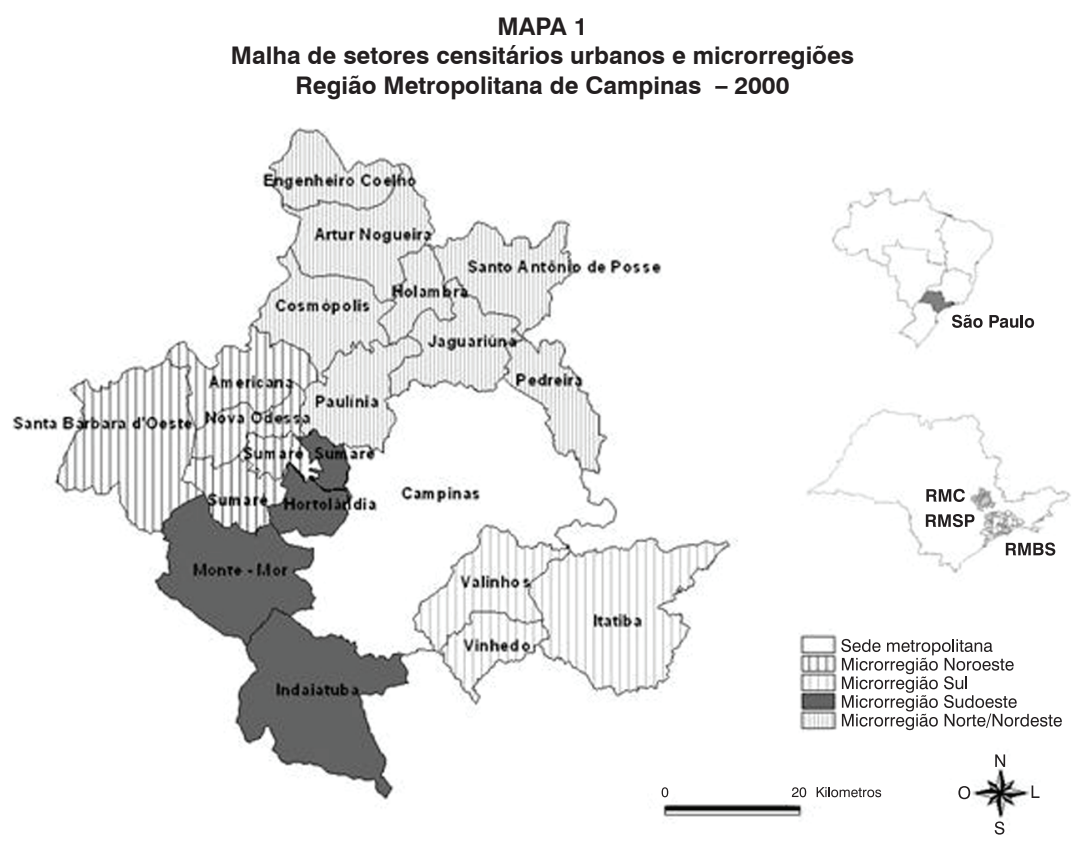

Fonte: Malha de setores, IBGE (2000).

malha viária, produzindo uma integração metropolitana bastante significativa.

Já a RMBS apresenta um quadro bastante diferenciado, mas que, igualmente, coloca a mobilidade e a integração regional no centro de sua constituição. Região litorânea, entre a serra e o mar, a estreita faixa de terra que envolve os nove municípios possui um formato linear bastante acentuado, não havendo a mesma capilaridade da sede, Santos, mas mantendo uma integração muito intensa por poucos caminhos. A conexão entre as cidades se dá toda pela SP-55, Rodovia Manoel da Nóbrega, e pela estrada que acompanha a orla, que possui muitas variações em sua infraestrutura ao longo da costa. Todo o trânsito se concentra em estreitos corredores viários, sempre no sentido paralelo à costa, deslocando-se dentro dos municípios e entre eles. Apenas na llha de São Vicente, onde estão Santos e a cidade de São Vicente, existe uma morfologia um pouco distinta, embora os morros, localizados no centro da ilha, garantam que se mantenha o sentido do contorno da costa como a orientação da urbanização (Mapa 2).
Há pelo menos duas situações espaciais bem claras em termos das interações espaciais entre as cidades: um eixo mais concentrado em Santos, que inclui São Vicente, Guarujá e Cubatão; e os demais municípios, que apresentam maior intensidade de atividades turísticas, uma urbanização menos densa e uma nítida relação entre a distância da sede e a intensidade dos processos e trocas populacionais.

Estes fatores, somados à história da própria ocupação da região muito mais antiga do que a de Campinas, associada de forma direta a toda a industrialização da Região Metropolitana de São Paulo, produziram uma concentração muito mais significativa. A ausência de outras conexões com outras cidades ou regiões que não sejam mediadas pela sede acentua um modelo de região metropolitana industrial: com muita concentração e dependência da sede frente ao seu entorno.

Essas configurações, evidentemente, se refletem nos modos de vida, na relação com os lugares e mediam a percepção dos perigos. 
MAPA 2

Malha dos setores censitários urbanos e microrregióes

Região Metropolitana da Baixada Santista - 2000

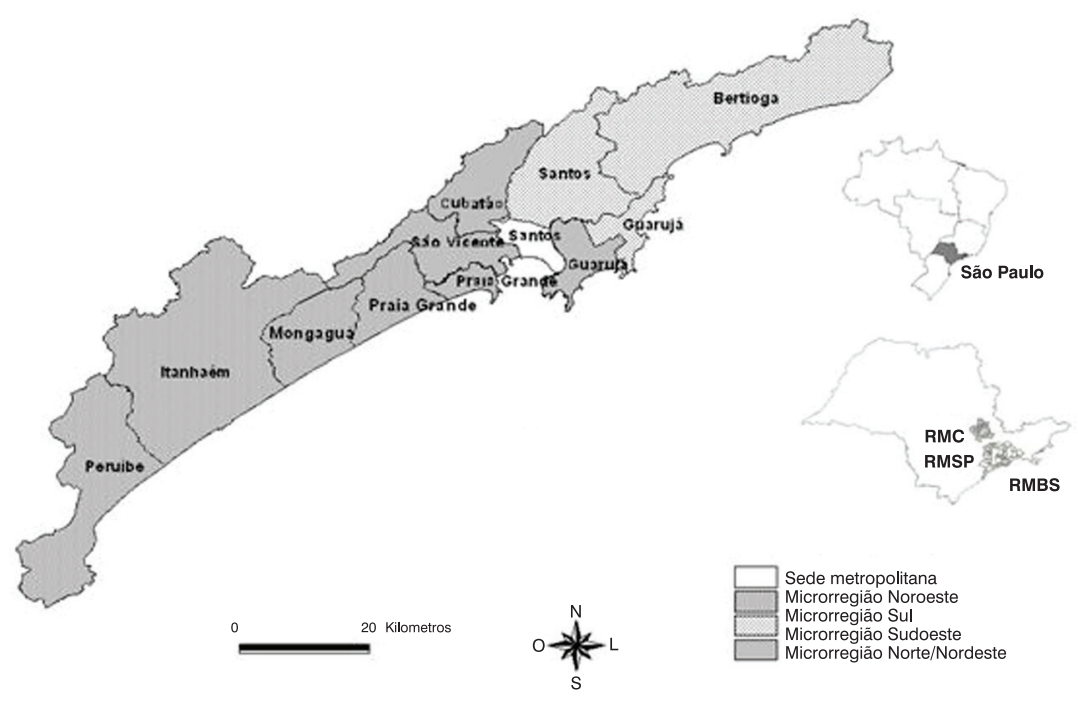

Fonte: Malha de setores, IBGE (2000).

Os 16 perigos sobre os quais se pediu a avaliação do informante sobre a gravidade para o entorno da residência foram agrupados em sete categorias, as quais permitem refletir sobre suas especificidades em termos de percepção (Quadro 1). Isso se fez necessário devido aos limites estatísticos de expansão da amostra, que podem comprometer sua representatividade. Por este mesmo motivo, também foram agrupados os gradientes de gravidade predefinidos como resposta para apenas grave ("muito grave" e "grave") e pouco grave ("pouco grave" e "nada grave"). Há uma proximidade cognitiva significativa entre muito grave e grave, e entre pouco grave e nada grave, o que justificou esta agregação. Como os dados para a categoria "não sabe" se mostraram insuficientes estatisticamente para serem considerados, utilizou-se apenas a informação contabilizada como "grave e muito grave" para fins de análise, identificando os perigos que sobressaíram em termos da gravidade.

As categorias revelam aspectos diferentes do envolvimento com o lugar e o papel da localização da sua percepção. As catego- rias contaminação e climáticos são aquelas em que a pessoa precisa ter em mente eventos específicos, devido à sua particularidade e concretude na experiência. Uma enchente não se dá de forma generalizada e nem indiscriminada. Trata-se de um evento facilmente identificável e tem duração e localização muito definidas. A contaminação também é definida espacialmente, embora seja mais difusa no tempo. Quando esta chega à percepção é porque foi legalmente notificada, divulgada e houve intervenção do poder público para sua contenção. Isso também marca um lugar específico. Estas duas categorias são também aquelas mais associadas ao ambiente, enquanto dimensão não urbana.

Já as categorias acessibilidade, qualidade de vida e trânsito dizem respeito ao cotidiano mais direto da pessoa. Sua percepção está associada diretamente a práticas e à própria experiência. Mesmo que não estejam ligadas a eventos específicos, elas se constroem de forma mais difusa na experiência, associadas a acontecimentos cotidianos. Elas possuem também, assim com as categorias infraestrutura e manu- 
QUADRO 1

Agregação das categorias de perigos ambientais urbanos

\begin{tabular}{ll}
\hline Acessibilidade & $\begin{array}{l}\text { Dificuldade de acesso a outros bairros } \\
\text { Dificuldade em chegar ao local de trabalho } \\
\text { Dificuldade de acesso à escola mais próxima } \\
\text { Dificuldade de ir ao posto de saúde mais próximo }\end{array}$ \\
\hline Climáticos & $\begin{array}{l}\text { Enchentes } \\
\text { Enxurradas } \\
\text { Deslizamentos }\end{array}$ \\
\hline Contaminação & Áreas contaminadas \\
\hline Infraestrutura & $\begin{array}{l}\text { Problemas no abastecimento de água } \\
\text { Problemas com saneamento e/ou esgoto }\end{array}$ \\
Manutenção & $\begin{array}{l}\text { Problemas na coleta do lixo } \\
\text { Insetos, ratos, carrapatos e pernilongos } \\
\text { Mato alto, terreno baldio }\end{array}$ \\
\hline Trânsito & Falta de locais de lazer nas proximidades \\
& Falta de áreas verdes nas proximidades \\
\hline
\end{tabular}

tenção, a percepção do papel do poder público e da sua intervenção na gestão do espaço público urbano, apontando para sua ausência, ao mesmo tempo em que qualificam esta ausência.

Quando se observam os dados agregados, ou seja, o conjunto das respostas dadas pelos informantes em cada RM, nota-se uma diferenciação clara entre as posições. O entorno da RMBS somou 25,0\% de respostas "grave", para o conjunto dos 16 perigos, o que é mais do que o dobro das demais posições. A sede da RMBS, por outro lado, registrou apenas $6,8 \%$, o menor índice entre as posições. $\mathrm{Na} \mathrm{RMC}$ foi a sede que acusou mais respostas como "grave e muito grave" (10,4\%), enquanto o entorno da RMC apontou 8,5\%.

Considerando-se os dados pelas categorias criadas, foi possível identificar melhor onde estão estas diferenças entre as posições (Gráficos 1 e 2). Em todas as categorias de perigos, as respostas para "grave e muito grave" do entorno da RMBS foram superiores às do entorno da RMC, enquanto as respostas da sede da RMC foram sempre maiores às da sede da RMBS. Destacam-se as porcentagens de respostas como "grave" do entorno da RMBS para contaminação $(31,0 \%)$, qualidade de vida (40,9\%) e manutenção (32,2\%), categorias com essa avaliação em, respectivamente, apenas $5,9 \%, 10,0 \%$ e $10,7 \%$ de respostas do entorno da RMC.

As maiores porcentagens de respostas "graves ou muito graves" na RMC foram dadas pela sede: $14,2 \%$ na categoria qualidade de vida; $14,8 \%$ para manutenção; e 14,3\% para trânsito. A categoria infraestrutura foi a única em que a resposta "grave ou muito grave" do entorno superou a da sede, com respectivamente $16,4 \%$ e $9,9 \%$.

Estas respostas apontam para o envolvimento com a região e a importância da proximidade em algumas regiões. $O$ entorno da RMBS é uma área com muitos assentamentos precários, muito afastados da sede, com problemas sérios de infraestrutura, acessibilidade e manutenção. As questões urbanas estão muito latentes, como aparecem na porcentagem da gravidade dos perigos relacionados a trânsito, manutenção e qualidade de vida, todos indicadores desta precariedade.

A exceção é a gravidade apontada para os perigos da contaminação na RMBS, em especial no entorno (na sede as respostas "grave e muito grave", nesta categoria, só 


\section{GRÁFICO 1}

Perigos ambientais urbanos percebidos como graves e muito graves, por categorias de perigos e posição (sede-entorno)

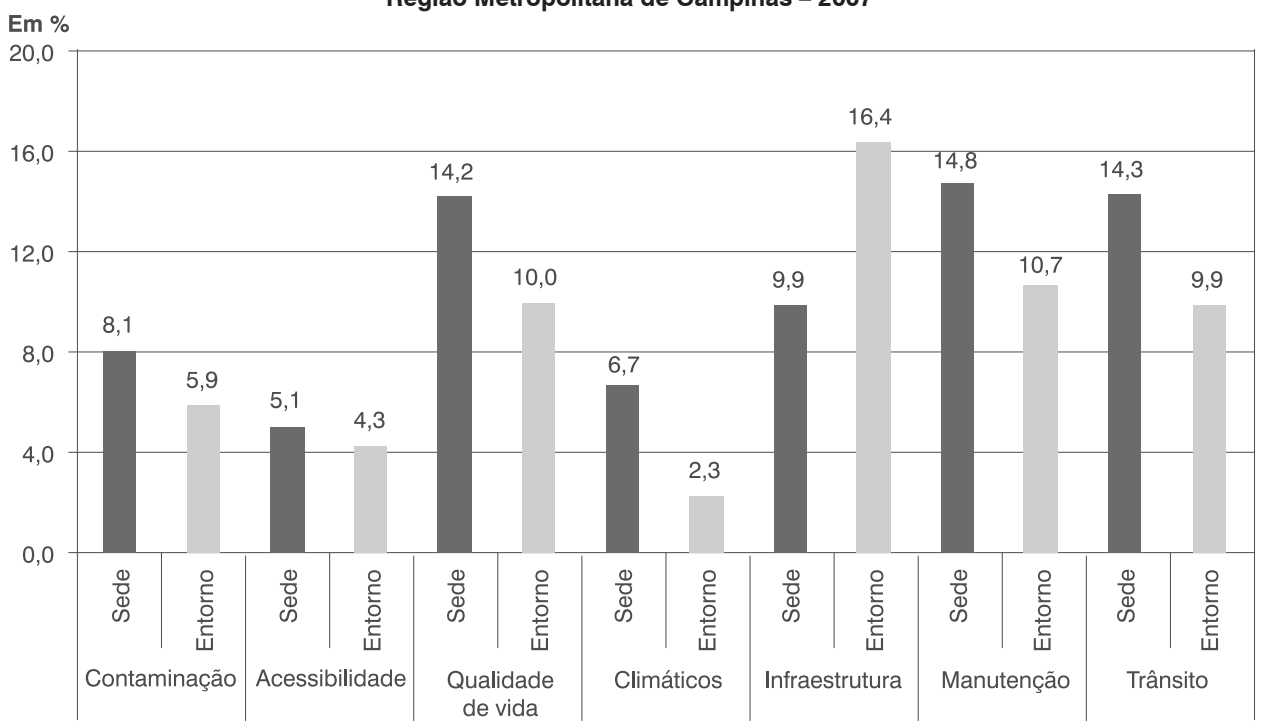

Fonte: Pesquisa domiciliar do Projeto Vulnerabilidade Fapesp/CNPq. Tabulações especiais, Nepo/Unicamp (2007)

\section{GRÁFICO 2}

Perigos ambientais urbanos percebidos como graves e muito graves, por categorias de perigos e posição (sede-entorno)

Fonte: Pesquisa domiciliar do Projeto Vulnerabilidade Fapesp/CNPq. Tabulações especiais, Nepo/Unicamp (2007).

somaram $8,1 \%$ ), que possui um histórico de áreas contaminadas que, mesmo já tendo se passado alguns anos, percebe-se que ainda está presente no imaginário da região. Os grandes eventos de contaminação ocorreram nas cidades do entorno, em 
especial Cubatão, e esta preocupação com a contaminação ainda presente não se dá apenas pela repercussão de casos antigos, mas também pelo ainda convívio com as consequências destas contaminações, principalmente para o mercado de trabalho e a saúde.

É interessante notar que, em ambas as regiões, independentemente da posição, os perigos climáticos não receberam destaque, sendo os aspectos do espaço construído muito mais latentes para as pessoas em termos da sua gravidade. Isso mesmo considerando-se que o levantamento domiciliar foi feito apenas poucos meses após a divulgação do Fourth Assessment Report (AR4) do International Panel on Climate Change (IPCC), ocasião em que o tema mudança climática estava sendo amplamente divulgado e discutido pela mídia. A acessibilidade também é muito pouco mencionada como um problema para as duas regiões, o que indica tanto uma articulada infraestrutura de mobilidade quanto uma rede de serviços relativamente bem distribuída.

A relação entre sede e entorno da RMC, por outro lado, é invertida. A maior densidade de deficiência de infraestrutura está na própria sede. Município com mais de um milhão de habitantes e com níveis de desigualdade elevados, Campinas ostenta uma ampla área de urbanização precária que se conurba com municípios vizinhos, repercutindo carências urbanas de toda ordem. A única categoria em que o entorno registrou mais respostas "grave" foi na infraestrutura, pois há muitas cidades da região com problemas crônicos de abastecimento e tratamento de efluentes, o que tem sido trabalhado, nos últimos anos, no município-sede.

Estas relações também se revelam quando se observam os dados da percepção dos perigos por escalas. Neste quesito, a estratégia na elaboração do questionário foi perguntar tanto pelos perigos, quanto por vantagens, entendidas enquanto o oposto ao perigo. Perguntamos para a escala do bairro, da cidade e da região ("A Sra. acha que há alguma vantagem em viver neste bairro/cidade/região?"), percebendo nuances importantes na qualidade das respostas.
Quando a resposta era positiva, permitia-se que a pessoa mencionasse livremente até três vantagens. Estas foram classificadas de acordo com categorias predefinidas. A Tabela 2 sintetiza as vantagens mais mencionadas.

As vantagens mostraram-se diretamente ligadas à questão locacional, de acessibilidade e de proximidade. $\mathrm{O}$ item "proximidade a qualquer serviço mencionado" recebeu as maiores frequências para quase todas as escalas, excetuando-se bairro na RMC e região na RMBS, embora nestes dois casos tenha sido a segunda mais mencionada. No primeiro caso, a mais mencionada foi "aluguel ou preço do terreno/casa", o que é uma vantagem locacional estrutural ligada à escolha do lugar de moradia, e no segundo caso foi a categoria "outros", cujo índice elevado aponta para o fato de que perdemos alguma dinâmica relevante.

É importante observar também os dados menores, tendo sido a categoria "espaços verdes" a menos mencionada nas duas RMs (o que é corroborado pelos altos índices de percepção de perigos ligados à qualidade de vida, cuja existência de espaços verdes está incluída), além do baixíssimo índice de respostas para "aluguel ou preço do terreno/casa" nas escalas da cidade e da região na RMBS. Chamam atenção também os baixos índices de respostas nestas mesmas escalas para "parentes próximos", categoria muito importante na RMC e na própria categoria bairro. Há, na percepção das vantagens nas escalas cidade e região na RMBS, uma importância na estrutura de serviços maior do que na RMC, onde fatores ligados ao cotidiano e à mobilidade apresentam-se mais relevantes em termos desta percepção.

O Gráfico 3 apresenta as respostas afirmativas agregadas para as duas RMs, mostrando uma percepção inversa na relação sede-entorno. Na RMC, é a sede que percebe mais as vantagens do que $o$ entorno, o que ocorre de forma inversa na RMBS, com uma amplitude bem maior. No geral, o índice de vantagem na sede da RMBS é muito baixo, com patamares entre $29 \%$ e $31 \%$ para as três escalas, enquanto seu entorno registra índices acima dos $50 \%$. 
Na RMC, a diferença é menor: na base de $38 \%-39 \%$ no entorno e $49 \%-53 \%$ na sede.

Há dois movimentos distintos nestes dados. Um é a constância entre as escalas (entorno da RMC e sede da RMBS). Isso aponta para uma percepção da posição e sua articulação entre as escalas. No caso do entorno da RMC, é o reconhecimento da articulação da região e de suas interações espaciais, ao passo que na sede da RMBS o peso da própria sede é preponderante no posicionamento escalar. Estar na sede é a principal vantagem.

Essa percepção também é revelada pelos dados da sede da RMC, que tem um índice muito alto nesta escala (53,0\%), em oposição aos $49,1 \%$ que apontaram vantagem em morar na região. Esse segundo

TABELA 2

Percepção das vantagens de morar no bairro, na cidade e na região Regiões Metropolitanas de Campinas e da Baixada Santista - 2007

Em porcentagem

\begin{tabular}{|c|c|c|c|c|c|c|}
\hline \multirow{2}{*}{ Vantagens } & \multicolumn{3}{|c|}{ RMC } & \multicolumn{3}{|c|}{ RMBS } \\
\hline & Bairro & Cidade & Região & Bairro & Cidade & Região \\
\hline Proximidade a qualquer serviço mencionado & 21,9 & 25,4 & 28,1 & 26,1 & 36,4 & 32,5 \\
\hline Qualidade de qualquer serviço mencionado & 9,0 & 14,3 & 17,4 & 10,1 & 18,1 & 15,5 \\
\hline Espaços verdes & 1,6 & 1,4 & 1,5 & 2,4 & 3,7 & 5,6 \\
\hline Segurança & 11,9 & 4,7 & 2,8 & 10,8 & 2,1 & 1,6 \\
\hline Parentes próximos & 21,2 & 19,9 & 17,4 & 19,2 & 9,4 & 6,6 \\
\hline Aluguel ou preço do terreno/casa & 25,1 & 16,4 & 14,9 & 13,7 & 1,6 & 0,6 \\
\hline Outros & 9,3 & 17,9 & 17,9 & 17,6 & 28,8 & 37,7 \\
\hline Total & 100,0 & 100,0 & 100,0 & 100,0 & 100,0 & 100,0 \\
\hline
\end{tabular}

Fonte: Pesquisa domiciliar do Projeto Vulnerabilidade Fapesp/CNPq. Tabulações especiais, Nepo/Unicamp (2007).

GRÁFICO 3

Percepção das vantagens de morar no bairro, na cidade e na região, por posição (sede-entorno) Regiões Metropolitanas de Campinas e da Baixada Santista - 2007

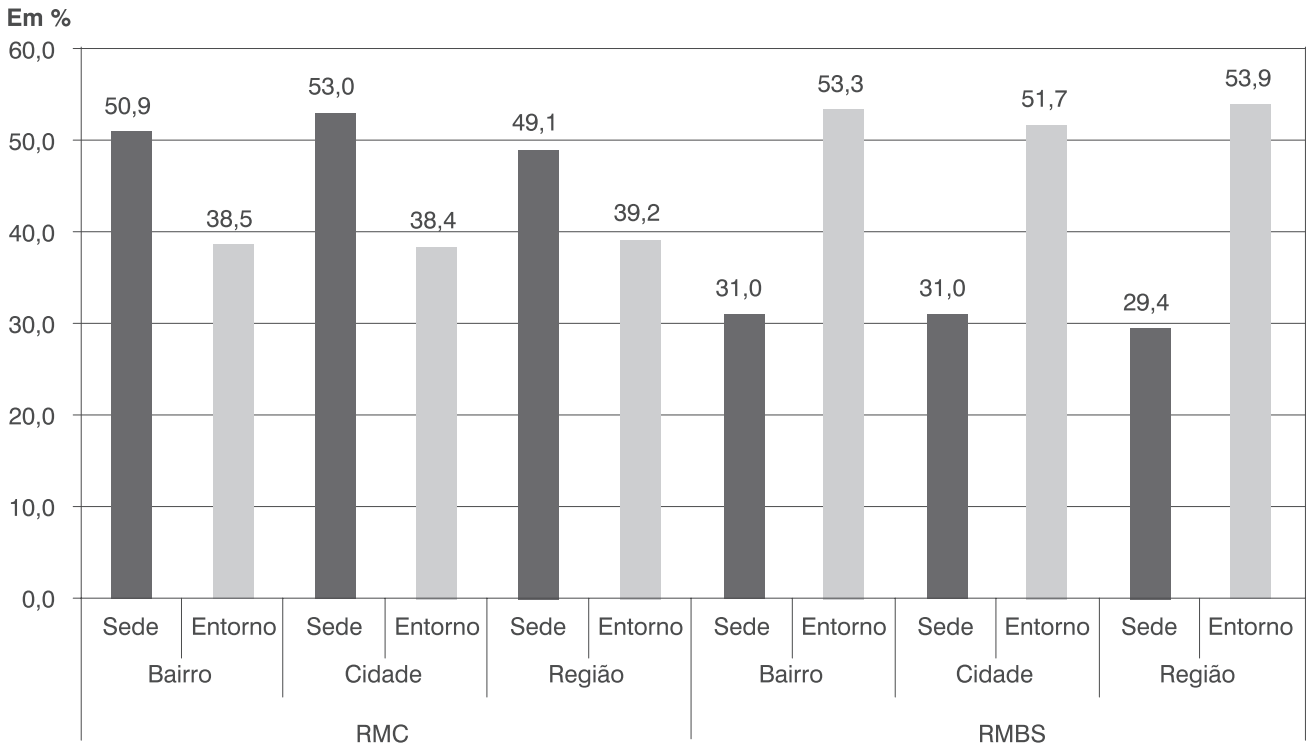

Fonte: Pesquisa domiciliar do Projeto Vulnerabilidade Fapesp/CNPq. Tabulações especiais, Nepo/Unicamp (2007). 
movimento, de reconhecimento maior entre as diferentes escalas, também se manifesta nos dados do entorno da RMBS, embora em menor grau, indicando a menor importância da cidade. Isso pode estar ligado à própria dimensão menor da RMBS e de sua forma urbana, que coloca na acessibilidade um peso muito forte na percepção da posição, já que a concentração na sede é maior e gera um fluxo significativo para ela.

Quanto à percepção dos perigos, a questão foi aplicada após a realização de uma pergunta separada sobre violência, pois os pré-testes haviam mostrado que a palavra perigo, nestas situações urbanometropolitanas, trazia imediatamente a dimensão da violência. Para captar outros perigos, portanto, primeiro perguntou-se sobre a violência, para depois indagar sobre os demais.

Neste caso, perguntamos apenas nas escalas do bairro e da cidade, pois as respostas aos perigos na RM, nos pré-testes, não se mostraram consistentes. Isso em si é importante, porque a reação das pessoas quando questionadas sobre os perigos no bairro, na cidade e por fim na RM era de indiferença ou de não entendimento. A diferença entre perigo no bairro (o entorno da casa) e na cidade (no seu cotidiano, mas não no seu "quintal") é muito clara para as pessoas e isso se reflete nas respostas. Já a RM parece uma escala em que os perigos não se manifestam, não aparecem na experiência. A região é difusa espacialmente e, embora as vantagens possam ser identificadas (especialmente pelas potencialidades da acessibilidade), os perigos não são percebidos nesta escala.

A pergunta feita ("E fora a violência, há algum outro perigo no seu bairro/cidade?") permitia primeiro a resposta sim ou não, com a especificação do perigo para as respostas sim. Assim como as vantagens, os perigos eram mencionados livremente, cabendo ao entrevistador classificar nas categorias predefinidas. Para fins de análise, tais perigos foram reunidos em categorias mais amplas, que expressam problemas semelhantes: inundação, enxurrada e deslizamento; poluição do ar; trânsito e acidentes de carro; manutenção (terrenos baldios, lixo e problemas sanitários); e outros. A distribuição pelas duas RMs pode ser vista na Tabela 3.

A poluição do ar e a manutenção foram os perigos mais mencionados na RMC, enquanto a manutenção e o trânsito foram os mais relevantes na RMBS. Isso aponta uma ressonância significativa com as particularidades das regiões, cujas formas urbanas intensificam tais problemas.

Quanto às diferenças escalares, chama atenção o fato de o índice de percepção do perigo referente à poluição do ar na RMC ser maior no bairro do que na cidade, o que indica uma percepção e experiência direta dele. A poluição do ar, em geral, é tratada como um problema difuso, concentrado nas regiões centrais ou corredores viários, mas o dado indica a concretude e proximidade do problema na percepção da população. Neste mesmo sentido, praticamente não há diferença na percepção do problema com

TABELA 3

Percepção dos perigos ambientais urbanos no bairro e na cidade Regiões Metropolitanas de Campinas e da Baixada Santista - 2007

Em porcentagem

\begin{tabular}{lrrrrr}
\hline \multirow{2}{*}{ Perigos ambientais urbanos } & \multicolumn{2}{c}{ RMC } & & \multicolumn{2}{c}{ RMBS } \\
\cline { 2 - 3 } \cline { 5 - 6 } \cline { 5 - 6 } Inundação, enxurrada, deslizamento & Bairro & Cidade & & Bairro & Cidade \\
\hline Poluição do ar & 5,4 & 18,9 & & 17,6 & 15,2 \\
Trânsito, acidentes de carro & $\mathbf{4 2 , 0}$ & $\mathbf{3 8 , 4}$ & & 4,1 & 5,7 \\
Manutenção: terrenos baldios, lixo, problemas sanitários & 14,9 & 15 & & 23,3 & $\mathbf{3 4 , 5}$ \\
Outros & 29,8 & 18,2 & & $\mathbf{4 7 , 2}$ & 32,9 \\
Total & 7,9 & 9,5 & & 7,8 & 11,7 \\
\hline
\end{tabular}

Fonte: Pesquisa domiciliar do Projeto Vulnerabilidade Fapesp/CNPq. Tabulações especiais, Nepo/Unicamp (2007). 
trânsito nas duas escalas, mostrando sua generalização no conjunto da RMC.

No reverso, perigos naturais ligados a eventos hidrometeorológicos (inundações, enxurradas e deslizamentos), na RMC, são mais identificados na cidade $(18,9 \%)$ do que no bairro $(5,4 \%)$, o que não acontece na RMBS, onde os índices para as duas escalas são muito próximos. $\mathrm{O}$ alto índice registrado na categoria manutenção inclui os problemas sanitários, historicamente presentes na RMBS e que marcam muito o cotidiano da urbanização precária presente amplamente na região.

Este perigo corresponde a boa parte dos $32,0 \%$ e $35,7 \%$ de perigos no bairro e na cidade, respectivamente, apontados pelo entorno da RMBS (Gráfico 4). A análise por posição mostra a mesma inversão vista nos dados de vantagens: a sede da RMC e o entorno da RMBS percebem mais perigos, sendo a sede da RMBS aquela que apresenta menores índices. Isso mostra que não há uma ligação direta entre perceber vantagens e perigos, ou seja, que uma elevada percepção de vantagens levaria a perceber menos perigos, ou vice-versa. Os dados apontam para um viés de lugar na percepção das questões ambientais. A sede da RMBS tem uma tendência geral de perceber menos tanto perigos quanto vantagens. Por quê? Essa é uma questão que está relacionada aos efeitos de lugar, que não aparecem nos dados.

\section{Condição migratória: tempo de residência}

Que é ser migrante? É estar em busca de uma nova territorialização, de conhecimento espacial e de inserção no lugar (MARANDOLA JR.; DAL GALLO, 2009). O migrante está em condições distintas em relação aos nativos em termos do tempo de envolvimento e na sua relação com o lugar (HERNÁNDEZ, 2007). Desde a já clássica compreensão de Norbert Elias (1994) sobre as diferenças entre os de fora e os estabelecidos, o fenômeno da migração tem sido visto também em seu processo de adaptação, o que implica uma reterritorialização (HAESBAERT, 1997; SAQUET, 2003).

GRÁFICO 4

Percepção dos perigos ambientais urbanos no bairro e na cidade, por posição (sede-entorno)

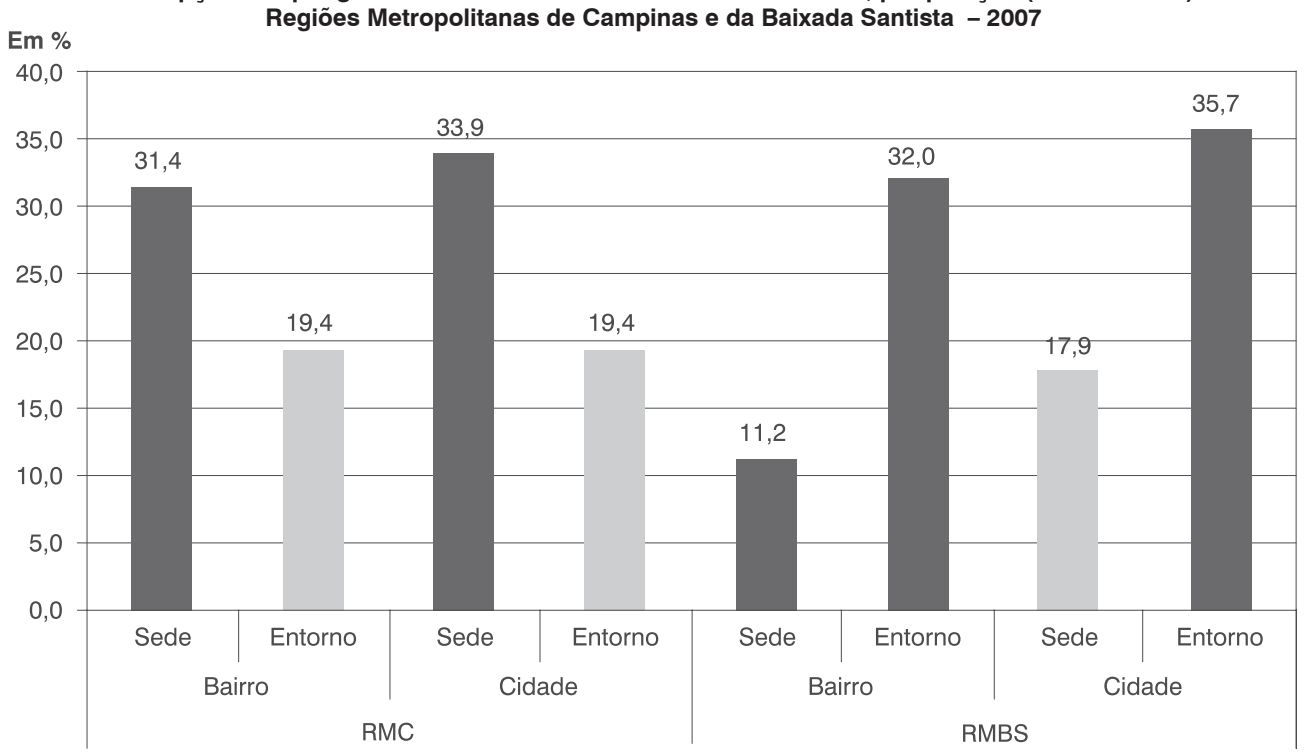

Fonte: Pesquisa domiciliar do Projeto Vulnerabilidade Fapesp/CNPq. Tabulações especiais, Nepo/Unicamp (2007). 
Em vista disso, o tempo de residência é um indicador adequado que mede o tempo de experiência na cidade, permitindo inferir diferenças entre o conhecimento espacial e o envolvimento com o lugar. Embora não seja possível por meio desta informação qualificar com muita precisão a natureza deste envolvimento, as pesquisas na região têm mostrado a diferença nos espaços de vida e na relação com os lugares entre migrantes e não migrantes (MARANDOLA JR., 2008a; 2008b; MARANDOLA JR.; HOGAN, 2009).

Por outro lado, as categorias dos perigos em discussão permitem identificar aspectos que dizem respeito às diferenças de envolvimento com os lugares mantidos por migrantes e não migrantes em regiões metropolitanas como estas, onde a migração dos últimos 20 anos advém de outras áreas urbanas. O que nossas pesquisas na região têm mostrado é que uma parcela significativa de migrantes possui familiares em outras cidades da RM, realizando viagens para visitá-los com certa frequência. Por outro lado, há um conjunto de migrantes de estrato médio que vivem na região sem parentes ou amigos da infância ou juventude, tendo se mudado a trabalho e que, em vista disso, precisam viajar frequentemente para o lugar-natal para manter os laços. Nestes casos, embora possam viver vários anos na região, estas pessoas podem manter-se vinculadas ao circuito de lugares metropolitanos - os lugares neutros de que fala Bauman (2001) -, onde é possível ficar à parte do sistema do local (MARANDOLA JR., 2008a; 2008b).

Isso gera uma situação extremamente complexa em termos da percepção dos perigos e sua aderência aos efeitos de lugar. De um lado, temos os naturais (não migrantes), enraizados nestas regiões antes da metropolização, antes dos grandes fluxos migratórios dos anos 1970 e antes dos migrantes mais recentes que vieram principalmente trabalhar em empresas ou procurar empregos em áreas de concentração urbana. De outro, há os migrantes, tanto os chegados há mais de dez anos (migrantes estabelecidos), que já possuem suas próprias redes e lugares na região que tendem a não coincidir com o sistema de lugares dos estabelecidos, como aqueles que chegaram há menos tempo (migrantes recentes), já com a metropolização completamente consolidada, e que têm acesso aos lugares e à informação de uma forma muito mediada, muito distantes do sistema de lugares dos não migrantes.

Esta situação é rica, no entanto, porque traz para o lugar outros lugares (pela memória e corporeidade dos migrantes), conectando o lugar a outros, pois diferente de outros períodos, estes são migrantes que vivem entre-territórios, mantendo ligações mais intensas (temporalmente e espacialmente) com seu lugar-natal (ALMEIDA, 2009). Isso agrega outra dimensão de envolvimento, diminuindo a dependência do lugar e o próprio tempo de experiência, já que as viagens podem ser, em alguns casos, extremamente frequentes.

Os dados permitem apreender alguns destes elementos quando se observa a percepção dos perigos ambientais urbanos, agora categorizados pelo tempo de residência. São os mesmos dados ora apresentados e, por isso, notam-se algumas permanências, como o destaque para o entorno da RMBS em apontar a gravidade dos perigos. No entanto, há também algumas tendências instigantes.

Por exemplo, observando-se os dados agregados para o conjunto das respostas, verifica-se que a percepção dos perigos é maior quanto menor for o tempo de residência. Em ambas as regiões, os respondentes que são migrantes recentes apontaram os perigos como graves ou muito graves mais vezes do que o fizeram os não migrantes. Estas proporções foram, respectivamente, de $11,1 \%$ e $8,5 \%$, na RMC, e de $20,9 \%$ e $15,9 \%$, na RMBS.

Estes dados indicam a importância do tempo de experiência no lugar para o enfrentamento dos perigos. Tempo de experiência possui uma associação não linear, mas crescente e positiva, com o envolvimento, a identidade e a dependência com/do lugar, como mostraram Hernández et al. (2007). A experiência ganha densidade e profundidade com o tempo, a partir da pausa (não mudanças), bem como pelos 
laços e atividades desenvolvidas tendo o lugar como mediação com o mundo (TUAN, 1983). Quanto maior for este envolvimento (o attachment), maior é a importância do lugar para a mediação das atitudes e percepções, inclusive dos perigos (TUAN, 1980; 2005).

Por outro lado, a percepção do perigo está diretamente associada à percepção do risco (DOUGLAS; WILDAVSKY, 1982) e esta, por sua vez, está ligada à capacidade de enfrentamento, ou seja, à vulnerabilidade (WISNER et al., 2004). O tempo de experiência e o envolvimento com o lugar (seja pela via da dependência seja pela identidade) aumentam o conhecimento espacial. A ausência deste é uma das origens da insegurança existencial e da incerteza, que estão intimamente ligadas à percepção do perigo (GIDDENS, 2002). A gravidade dos perigos, portanto, é atenuada diante do conhecimento do perigo, mais do que isso, do conhecimento dos lugares onde estão o perigo e das práticas necessárias para enfrentá-lo (MARANDOLA JR., 2008b).
Outro dado importante neste olhar mais geral sobre a percepção dos perigos por condição migratória é a diferença entre as duas RMs, além do fato de aquela discrepância entre sede e entorno da RMBS ter se dissipada num maior equilíbrio entre as categorias de migrantes, o que reforça a importância da diferença entre estes dois lugares no caso desta região.

Já o foco na especificidade das diferentes categorias de perigo e sua influência nestes dados mais gerais mostra como a condição migrante interfere na percepção de cada perigo. Na RMC, os migrantes recentes apresentaram os maiores índices de percepção de gravidade do perigo em relação a três categorias (contaminação, qualidade de vida e manutenção), enquanto os não migrantes o fizeram com relação aos perigos ligados ao trânsito e à categoria climáticos e os migrantes estabelecidos (que vivem na região há dez ou mais anos) registraram índices maiores em acessibilidade e infraestrutura (Gráfico 5).

GRÁFICO 5

Perigos ambientais urbanos percebidos como graves e muito graves, por categorias de perigos e condição migratória (tempo de residência)

Região Metropolitana de Campinas - 2007

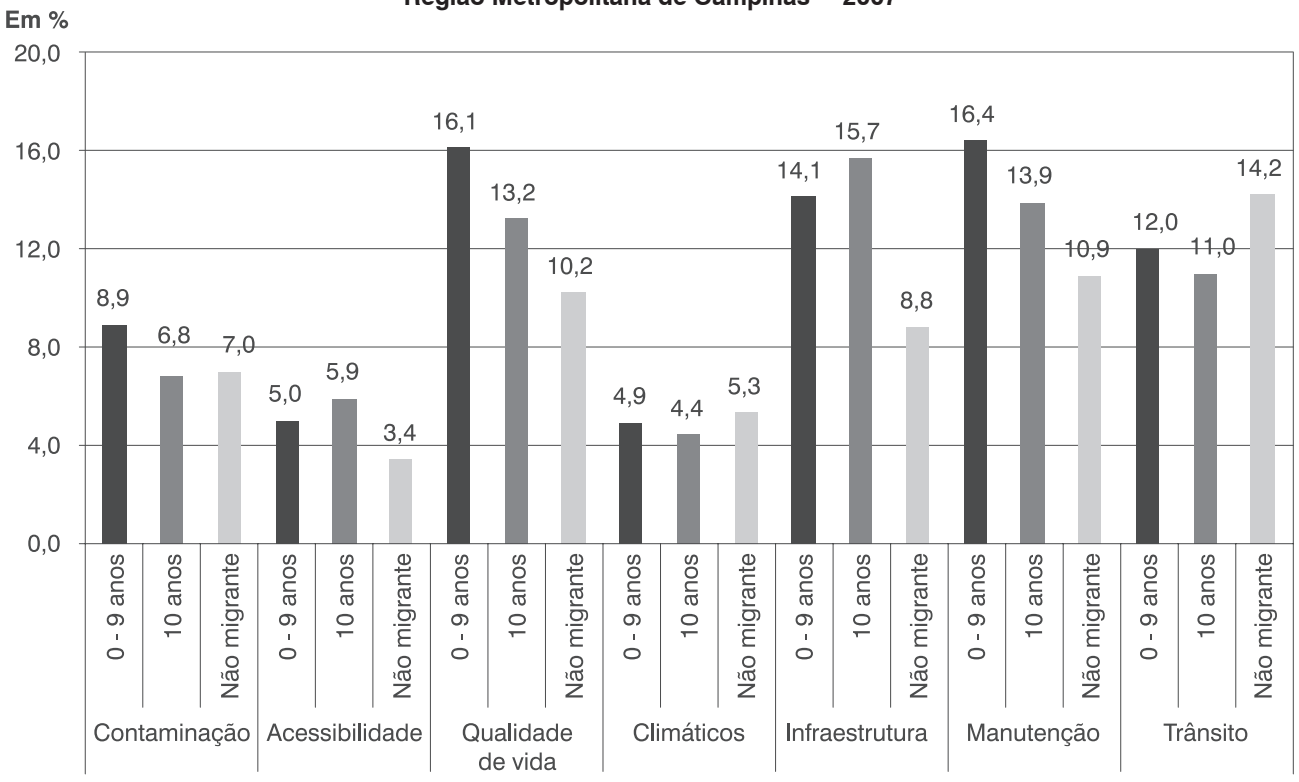

Fonte: Pesquisa domiciliar do Projeto Vulnerabilidade Fapesp/CNPq. Tabulações especiais, Nepo/Unicamp (2007). 
Na RMBS, os migrantes recentes tiveram maior número de respostas de perigos graves e muito graves nas categorias contaminação, climáticos, infraestrutura e manutenção, enquanto os migrantes estabelecidos sobressaíram nas categorias acessibilidade, qualidade de vida e trânsito (Gráfico 6).

Observa-se, assim, que não há correspondência, entre as regiões, da condição migratória determinando a relação com os perigos específicos. Isso se dá pelas características destas regiões e das suas diferentes posições. Os efeitos de lugar, neste caso, são muito mais topológicos e referem-se às características próprias dos lugares que colocam migrantes, não migrantes e migrantes estabelecidos em condições diferentes diante de cada perigo. As únicas categorias de perigos que mantiveram a mesma distribuição por condição de migração foram acessibilidade e manutenção, podendo-se incluir também qualidade de vida, que teve uma diferença irrisória na posição entre migrantes recentes e migrantes estabelecidos na RMBS. Os perigos que estão reunidos nestas categorias referem-se ao cotidiano, o que tem um viés direto da condição migratória. Mesmo a categoria manutenção tem relação com a situação do bairro no uso do espaço público.

Um destaque merece a categoria qualidade de vida, pois a RMBS, por se tratar de uma região litorânea, tem a praia como principal espaço público. Os altos índices de resposta para "grave e muito grave", neste caso, revelam a condição do conjunto da cidade, com a praia sendo o único espaço público na maioria das cidades e nem sempre acessível, devido à distância e à própria ausência de meios de transporte público no sentido perpendicular à linha da costa (os bairros mais pobres se estendem em direção à serra, afastando-se do mar).

Os dados da percepção das escalas ajudam a avançar nessa discussão. 0 Gráfico 7 mostra os dados da percepção da vantagem de morar no bairro, na cidade e na RM, por condição migratória. Em todas as escalas, nas duas RMs, os migrantes estabelecidos foram os que apontaram mais vantagens, sendo que os migrantes recentes

GRÁFICO 6

Perigos ambientais urbanos percebidos como graves e muito graves, por categorias de perigos e condição migratória (tempo de residência)

Região Metropolitana da Baixada Santista - 2007

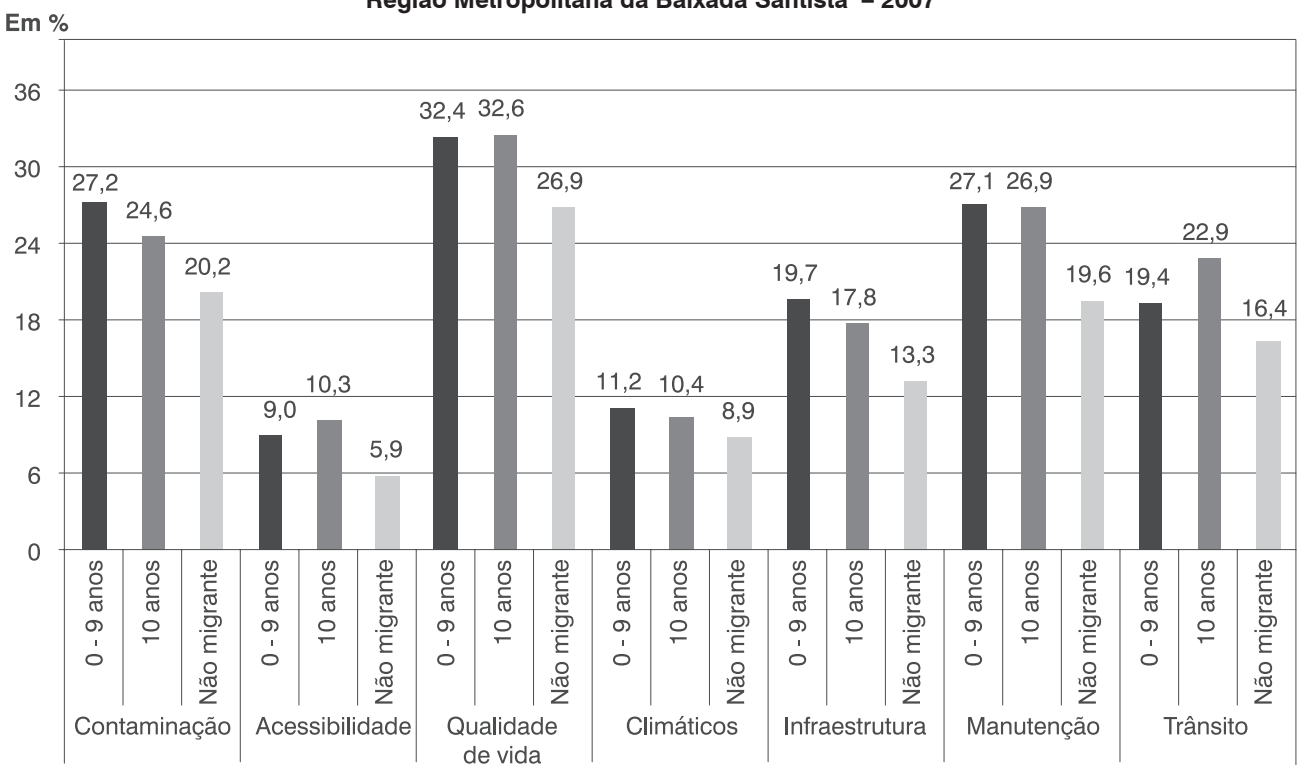

Fonte: Pesquisa domiciliar do Projeto Vulnerabilidade Fapesp/CNPq. Tabulações especiais, Nepo/Unicamp (2007). 
sempre tiveram os menores índices. Em termos das escalas, há uma constância nas duas RMs em relação à proporção entre os grupos de condição migrante, o que indica uma conexão cognitiva entre as vantagens do bairro com a cidade e a região.

Os dados indicam a não associação entre a mudança para a região e a percepção de vantagens. Se esta aumenta com o tempo de permanência, como se observa nos dados, ela tem uma relação mais direta com a experiência e o envolvimento com o lugar, e não com a imagem projetada por ele enquanto atrativo.

O mesmo ocorre com relação aos perigos. O Gráfico 8 mostra claramente que os migrantes recentes identificam os perigos como graves e muito graves em patamares bem menores. A diferença em relação às vantagens é que, na $\mathrm{RMC}$, são os não migrantes que apresentam o maior índice, com os migrantes estabelecidos em patamares bem próximos e os migrantes recentes com níveis menores ainda de percepção dos perigos do que da percepção das vantagens.
Se pensarmos nos perigos que foram mais apontados como "graves e muito graves" (Tabela 3), notamos a importância que a poluição do ar tem nos dados da RMC, denotando alteração e intensificação nos últimos anos, que têm sido percebidas ao longo do tempo. No caso da RMBS, o perigo mais apontado foi manutenção, para o bairro, e trânsito, para a cidade, o que não representa um viés de tempo de residência específico, mas sim um efeito de lugar mais contextual.

\section{Efeitos de lugar nos estudos de P-A}

O esforço desta pesquisa é o de avançar em conjunto em termos teóricos e metodológicos, procurando movimentar temas específicos com metodologias de integração de abordagens que contribuam para pensarmos as questões de P-A de forma ampla e que contribua para os estudos populacionais. Diante de suas limitações, o processo de pesquisa e sua construção metodológica aqui discutidos são relevantes para a problematização dos desafios que o

GRÁFICO 7

Percepção de vantagem de morar no bairro, na cidade e na RM, por condição migratória (tempo de residência) Regiões Metropolitanas de Campinas e da Baixada Santista - 2007

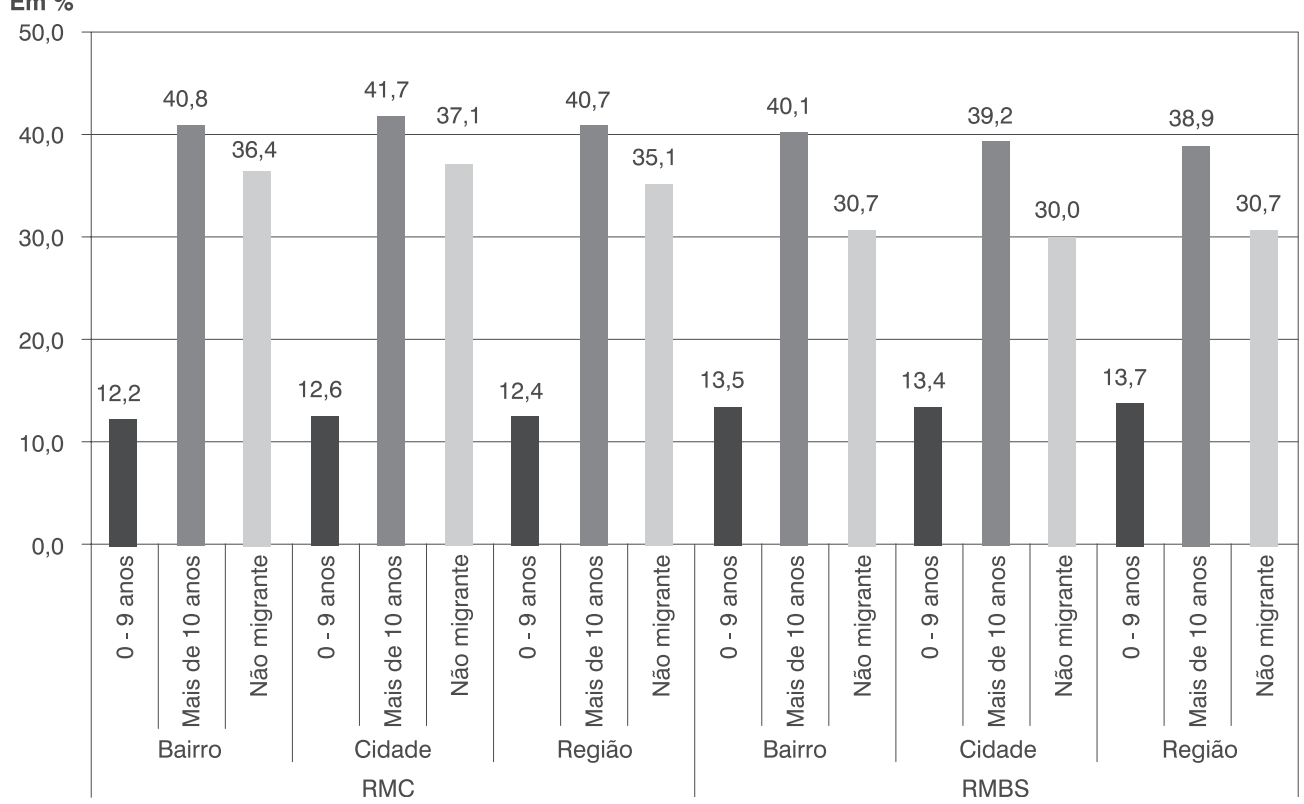

Fonte: Pesquisa domiciliar do Projeto Vulnerabilidade Fapesp/CNPq. Tabulações especiais, Nepo/Unicamp (2007). 


\section{GRÁFICO 8}

Percepção dos perigos ambientais urbanos no bairro e na cidade, por condição migratória (tempo de residência) Regiões Metropolitanas de Campinas e da Baixada Santista - 2007

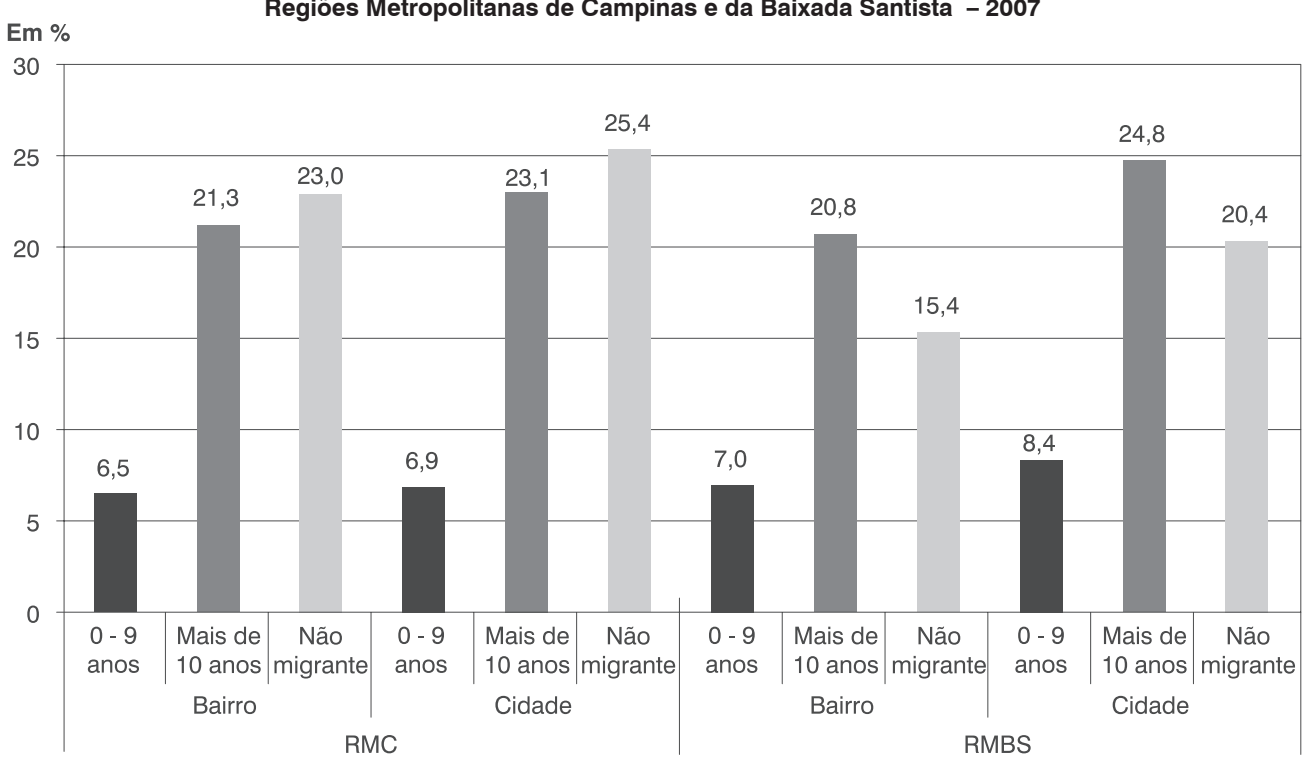

Fonte: Pesquisa domiciliar do Projeto Vulnerabilidade Fapesp/CNPq. Tabulações especiais, Nepo/Unicamp (2007).

campo P-A tem enfrentado, em seu conjunto, para extrapolar limites colocados pelas próprias bases de dados e metodologias convencionais.

Em vista disso, a estratégia de combinar trabalhos verticalizados com aplicação de metodologias qualitativas (de orientação fenomenológica) com resultados de levantamentos de percepção colhidos em larga escala (duas RMs) é um esforço para identificar elementos nas duas frentes, colocando um a serviço do outro para a discussão do espaço na relação P-A.

Este trabalho mostra muitas das possibilidades e também muitas das lacunas deste esforço. Se, por um lado, podemos ver com clareza os efeitos de lugar influenciando a percepção dos perigos ambientais urbanos, por outro, ficamos devendo uma incursão mais analítica de outras variáveis demográficas na composição dos próprios efeitos. Condição migratória é relevante, mas não suficiente para esta incursão, assim como não é, em si, o reconhecimento do viés de gênero dos dados. Mas, pelo desenho amostral da pesquisa, não se pode avançar muito além, pois esbarramos nas limitações estatísticas.

Entre os aspectos que ficam muito evidentes, está o papel do lugar na percepção dos perigos. Tanto o corte por posição e condição migratória quanto a consideração das percepções pelas escalas indicam a importância do lugar, em seu sentido amplo. A operacionalização de pesquisas com dados empíricos sempre provoca certas escolhas de recortes que ressaltam alguns aspectos. Neste caso, vemos claramente que os elementos tangenciais dos efeitos de lugar, escolhidos para evidenciar seu papel, são significativos o suficiente para não serem ignorados. Se, por um lado, a natureza tangencial não permite precisar alguma medida de impacto ou uma metrificação de sua natureza (como os estudos psicométricos), por outro, tais levantamentos reforçam e coadunam com as pesquisas qualitativas de profundidade e as formulações teóricas delas oriundas.

Por outro lado, estes estudos apontam questões antes não consideradas, como a especificidade da sede da RMBS em perce- 
ber menos tanto perigos quanto vantagens, ou os baixos índices de percepção de questões que a teoria urbana constantemente reforça, como a importância de parentes próximos e dos valores da terra urbana, que nos dados para cidade e região, na RMBS, não possuem relevância.

Outra questão central que a discussão dos dados aponta é a mistura, no caso da percepção, dos perigos ambientais relacionados a eventos naturais e os de origem da produção humana (man-made). Os perigos são mais percebidos pela questão espacial da localização, segundo proximidade e distância, quando se referem a eventos do seu cotidiano, diferente de quando se pensa em perigos que são mais difusos, tanto no tempo quanto no espaço, que tendem a ser percebidos mais pelas mediações socioculturais.

Isso aponta para a importância de fatores materiais, sociais e individuais na composição e consideração dos efeitos de lugar. Estes não se resumem às trajetórias individuais, nem à configuração material estrutural. É na compreensão da forma específica de configuração destes fatores que as diferenças se configuram, o que explica as distinções entre as posições.

Já a condição migratória se mostra uma excelente categoria para analisar as questões de perigos e para pensar os efeitos de lugar. A condição coloca as pessoas em posição diferencial no espaço, o que institui níveis de envolvimento, dependência e identidade muito variáveis. Por seu turno, é lamentável que os dados não permitam avançar na análise das percepções por critérios mais específicos, como a origem dos migrantes, ou mesmo por uma escala de tempo de residência menor. Isso possibilitaria considerar de forma mais precisa as influências e o peso do lugar de origem nas percepções e suas formas de ver e entender o mundo. Outros fatores demográficos também seriam potencialmente elucidativos destes efeitos, como a estrutura familiar, o estágio do ciclo vital e o seu padrão de mobilidade.

O tempo de residência, portanto, é extremamente relevante para discutir os efeitos de lugar em termos da dinâmica P-A, podendo trazer uma série de questões referentes ao espaço, à estrutura urbana e à própria dinâmica demográfica. Juntamente com ele, a própria questão da escala torna-se mais forte e evidente, permitindo pensar a experiência na região, na cidade e no bairro, o que qualificaria mais ainda os dados aqui analisados.

Região, cidade e lugar mostraram-se, por seu turno, escalas espaciais necessárias aos estudos de P-A, para compreender e conectar as escalas de percepção, estruturação e produção do espaço. É difícil pensar a não aderência, tanto em estudos urbanos quanto rurais, destas escalas que conectam a efetivação dos perigos na experiência com sua organização e distribuição de forma mais difusa, no tempo e no espaço. Proximidade e distância são questões que os estudos de P-A precisam trazer com mais força quando estão pensando a dimensão do espaço em seus processos.

O desafio é conseguir tal articulação com bases de dados adequadas. Para isso é necessário investir em levantamentos específicos e em pesquisas que permitam a análise transescalar e que dialoguem e se retroalimentem. O fantasma da falácia ecológica só voltará a rondar os estudos de P-A com mais força se mantivermos a pesquisa no tema engessado em uma das escalas, seja a micro, seja a macro. A maior força da falácia ecológica está na ilusão de que o espaço é homogêneo e que não há fenômenos de ordens diferentes que não são apreensíveis com os métodos empregados. Evitá-la, portanto, implica uma análise transescalar que não considere as escalas mais próximas como determinadas pelas mais distantes, nem o inverso.

Uma das virtudes dos estudos de P-A no campo da Demografia tem sido a incorporação do espaço como uma dimensão propriamente demográfica dos fenômenos: os efeitos de lugar são uma especificação desta espacialidade, manifesta em escalas diferentes e com processos de constituição, manutenção e difusão diferenciados. Explorá-los em par com as componentes da dinâmica demográfica é uma necessidade para a consolidação metodológica da consideração do espaço na relação P-A nos estudos populacionais. 


\section{Referências}

ALMEIDA, M. G. Diáspora: viver entreterritórios. E entre-culturas? In: SAQUET, M. A.; SPOSITO, E. S. (Orgs.). Territórios e territorialidades: teorias, processos e conflitos. São Paulo: Expressão Popular, 2009, p.175-195.

BARBIERI, A. F. Mobilidade populacional, meio ambiente e uso da terra em áreas de fronteira: uma abordagem multiescalar. Revista Brasileira de Estudos de População, v. 24, n. 2, p. 225-246, 2007.

BAUMAN Z. Modernidade Líquida. Rio de Janeiro: Jorge Zahar, 2001.

Comunidade: a busca por segurança no mundo atual. Trad. Plínio Dentzien. Rio de Janeiro: Jorge Zahar, 2003.

A sociedade individualizada: vidas contadas e histórias vividas. Trad. José Gradel. Rio de Janeiro: Jorge Zahar, 2008.

BOURDIN, A. A questão local. Trad. Orlando dos Reis. Rio de Janeiro: DP\&A, 2001.

CAIADO, M. C. S.; PIRES, M. C. S. Campinas metropolitana: transformações na estrutura urbana atual e desafios futuros. In: CUNHA, J. M. P. da (Org.). Novas metrópoles paulistas: população, vulnerabilidade e segregação. Campinas: Nepo/Unicamp, 2006, p. 275-304.

CASTIEL, L. D. Lidando com o riso na era midiática. In: MINAYO, M. C. de S.; MIRANDA, A. C. de (Orgs.). Saúde e ambiente sustentável: estreitando nós. Rio de Janeiro: Fiocruz, 2002, p. 113-133.

CASTRO, M. G.; ABRAMOVAY, M. Gênero e meio ambiente. São Paulo: Cortez; Brasília: Unesco; Unicef, 2005.

CUNHA, J. M. P. da; JAKOB, A. A. E.; HOGAN, D. J.; CARMO, R. L. do. A vulnerabilidade social no contexto metropolitano: o caso de Campinas. In: CUNHA, J. M. P. da (Org.). Novas metrópoles paulistas: população, vulnerabilidade e segregação. Campinas: Nepo/Unicamp, 2006, p.143-168.

. Introdução. In: CUNHA, J. M. P. da (Coord.); MARANDOLA JR., E.; OJIMA, R..
(Orgs.) Região Metropolitana de Campinas: sumário de dados. Campinas: Nepo-Unicamp, 2009, p. 4-10.

D'ANTONA, Á. de O.; CAK, A. D.; VANWEY, L. K. Efeitos da escala da análise em estudos de mudança da cobertura da terra entre Santarém e Altamira, no Pará, Brasil. In: HOGAN, D. J. (Org.). Dinâmica populacional e mudança ambiental: cenários para o desenvolvimento brasileiro. Campinas: Nepo/Unicamp, 2007, p. 87-113.

DARDEL, E. L'homme et la Terre: nature de la réalité géographie. Paris: PUF, 1952.

DE PAULA, F. C.; MARANDOLA JR., E.; HOGAN, D. J. O bairro, lugar na metrópole: riscos e vulnerabilidades no São Bernardo, Campinas. Caderno de Geografia, v. 17, p. 31-58, 2007.

DOUGLAS, M. Risk, acceptability according to the social sciences. New York: Russell Sage Foundation, 1985.

Les éstudes de perception du risque: un état de l'art. In: FABIANI, J-L.; THEYS, J. (Orgs.). La société vulnérable: évaluer et maîtriser les risques. Paris: Presses de L'École Normale Supérieure, 1987, p.55-60.

DOUGLAS, M.; WILDAVSKY, A. Risk and culture: an essay on the selection of technological and environmental dangers. Berlekey: University of California, 1982.

DUNCAN, J. O supraorgânico na geografia cultural americana. Espaço e Cultura, Rio de Janeiro, Nepec, n.13, p.7-33, jan./jun. 2002.

ELIAS, N. A sociedade dos indivíduos. Trad. Vera Ribeiro. Rio de Janeiro: Jorge Zahar, 1994.

ENTWISLE, B. Putting people into place. Demography, v. 44, n. 4, p. 687-703, 2007.

ENTRIKIN, J. N. The betweenness of place: towards a geography of modernity. Baltimore: The Johns Hopkins University Press, 1991.

FINUCANE, M. L.; SLOVIC, P.; MERTZ, C. K.; FLYNN, J.; SATTERFIELD, T. A. Gender, 
race, and perceived risk: the "white male" effect. Health, Risk \& Society, n. 2, p.159172, 2000.

FLYNN, J.; SLOVIC, P.; MERTZ, C. K. Race, and perception of environmental health risks. Risk Analysis, v. 14, n. 6, p. 1.1011.108, 1994.

GIBSON, J. J. The perception of the visual world. Westport: Greenwood Press, 1974.

GIDDENS, A. Modernidade e identidade. Trad. Plínio Dentzien. Rio de Janeiro: Jorge Zahar, 2002.

GREENBERG, M.; SCHNEIDER, D. Gender differences in risk perception: effects differ in stressed vs. non-stressed environments. Risk Analysis, n. 15, p. 503-511, 1995.

GUSTAFSON, P. E. Gender differences in risk perception: theoretical and methodological perspectives. Risk Analysis, v. 18, n. 6, p. 805- 811, 2006.

HAESBAERT, R. Des-territorialização e identidade: a rede gaúcha no Nordeste. Niterói: Eduff, 1997.

HENWOOD, K. L.; PARKHILL, K. A.; PIDGEON, N. F. Science, technology and risk perception: from gender differences to the effects made by gender. Emerald, v. 27, n. 8, p. 662- 676, 2008.

HERNÁNDEZ, B. et al. Place attachment and place identity in natives and non-natives. Journal of Environmental Psychology, n. 27, p. 310-319, 2007.

HOGAN, D. J. A relação entre população e ambiente: desafios para a demografia. In: TORRES, H. da G.; MOURA, H. da C. (Orgs.). População e meio ambiente: debates e desafios. São Paulo: Senac, 2000, p. 21-52.

JAKOB, A. A. E. Análise sócio-demográfica da constituição do espaço urbano da Região Metropolitana da Baixada Santista no período 1960-2000. Tese (Doutorado em Demografia) - Instituto de Filosofia e Ciências Humanas, Universidade Estadual de Campinas, 2003.

KASPERSON, J. X.; KASPERSON, R. E. The social contours of risk: publics, risk communication \& the social amplification of risk. London: Earthscan, 2005.

KATES, R. W. The perception of storm hazard on the shores of megalopolis. In: LOWENTHAL, D. (Ed.). Environmental perception and behavior. The University of Chicago, Department of Geography, 1967, p.60-74 (Research paper, n. 109).

KYLE, G. et al. Effects of place attachment on user's perception of social and environmental conditions in a natural setting. Journal of Environmental Psychology, n. 24, p. 213225, 2004.

LEWICKA, M. Place attachment, place identity, and place memory: restoring the forgotten city past. Journal of Environmental Psychology, n. 28, p. 209-231, 2008.

. What makes neighborhood different from home and city? Effects of place scale on place attachment. Journal of Environmental Psychology, n. 30, p. 35-51, 2010.

LINDELL, M. K.; HWANG, S. N. Households' perceived personal risk and responses in a multihazard environment. Risk Analysis, v. 28, n. 2, p. 539-556, 2008.

LOW, S. M.; ALTMAN, I. Place attachment: a conceptual inquiry. In: ALTMAN, I.; LOW, S. M. (Eds.). Place attachment. New York: Plenum Press, 1992, p. 1-12.

LOWENTHAL, D. Past time, present place: landscape and memory. Geographical Review, n. 65, p. 1-37, 1975.

LUHMANN, N. Risk: a sociological theory. Trad. Barrett R. New York: Aldine de Gruyuter, 1993.

LUPTON, D. Risk. London: Routledge, 1999.

LUTZ, W.; PRSKAWETZ, A.; SANDERSON, W. C. Introduction. In: LUTZ, W.; PRSKAWETZ, A.; SANDERSON, W. C. (Eds.). Population and environment: methods of analysis. New York: Population Council, 2002, p. 1-21 (Population and Development Review - a supplement to volume 28).

LYNCH, K. A imagem da cidade. São Paulo: Martins Fontes, 2003. 
MACINTYRE, S.; ELLAWAY, A.; CUMMINS, $S$. Place effects on health: how can we conceptualise, operationalise and measure them? Social Science \& Medicine, n. 55, p. 125-139, 2002.

MARANDOLA JR., E. Habitar em risco: mobilidade e vulnerabilidade na experiência metropolitana. Tese (Doutorado em Geografia) - Instituto de Geociências, Universidade Estadual de Campinas, 2008a.

. Entre muros e rodovias: os riscos do espaço e do lugar. Antropolítica, n. 24, p. $195-217,2008 b$.

. Insegurança existencial e vulnerabilidade no habitar urbano. Caderno de Geografia, v. 18, p. 39-58, 2008c.

MARANDOLA JR., E.; DAL GALLO, P. M. Ser migrante: implicações territoriais e existenciais da migração. In: ENCONTRO NACIONAL SOBRE MIGRAÇÕES, 6. Anais... Belo Horizonte: Associação Brasileira de Estudos Populacionais, 2009. Disponível em: $<$ http://www.abep.nepo.unicamp.br/docs/ anais/outros/6EncNacSobreMigracoes/ST3/ Marandola_2.pdf $>$.

MARANDOLA JR., E.; HOGAN, D. J. Em direção a uma demografia ambiental? Avaliação e tendências dos estudos de população e ambiente no Brasil. Revista Brasileira de Estudos de População, v. 24, n. 2, p. 191 223, jul./dez. 2007a.

Vulnerabilities and risks in population and environment studies. Population and Environment, v. 28, p. 83-112, 2007b.

. Vulnerabilidade do lugar vs. vulnerabilidade sociodemográfica: implicações metodológicas de uma velha questão. Revista Brasileira de Estudos de População, v. 26, n. 2, p. 161-191, jul./dez. 2009.

MARTINE, G. Introdução - A demografia na questão ecológica: falácias e dilemas reais. In: MARTINE, G. (Org.). População, meio ambiente e desenvolvimento: verdades e contradições. Campinas: Ed. da Unicamp, 1993. p. 9-19.

The sustainable use of space:

advancing the population/environment agenda. Paper presented at the Cyber Seminars of the Population-Environment Research Network, 2001. Disponível em: $<$ http://www.populationenvironmentresearch. org $>$.

O lugar do espaço na equação população/meio ambiente. Revista Brasileira de Estudos de População, v. 24, n. 2, p. 181-190, jul./dez. 2007.

NEPO/UNICAMP - Núcleo de Estudos de População/Universidade Estadual de Campinas. Atlas da Região Metropolitana da Baixada Santista. Campinas: Nepo/Unicamp, 2006. Disponível em: <http://www. nepo.unicamp.br/vulnerabilidade/atlas/ atlas_santos/Atlas_Final/index.htm > .

NIELSEN-PINCUS, M. et al. Sociodemographic effects on place bonding. Journal of Environmental Psychology, p. 1-12, 2010 [in press].

OLIVEIRA, L. de. Contribuição dos estudos cognitivos à percepção geográfica. Geografia, Rio Claro, v. 2, n. 3, p. 61-72, 1977.

PINHEIRO, J. Q. Psicologia ambiental: a busca de um ambiente melhor. Estudos de Psicologia, v. 2, n. 2, p. 377-398, 1997.

Mapas cognitivos de mundo, tempo na experiência ambiental, lugar e sustentabilidade. In: OLIVEIRA, L.; FERREIRA, Y. N.; GRATÃO, L. H. B.; MARANDOLA JR., E. (Orgs.). Geografia, percepção e cognição do meio ambiente. Londrina: Edições Humanidades, 2006. p. 67-100.

PIRES, M. C. S. Morar na metrópole: expansão urbana e mercado imobiliário na Região Metropolitana de Campinas. Tese (Doutorado em Geografia) - Instituto de Geociências, Universidade Estadual de Campinas, 2007.

RELPH, E. Place and placelessness. London: Pion, 1976.

RIECHARD, D. E.; PETERSON, S. J. Perception of environmental risk related to gender, community socioeconomic setting, age, and locus of control. Journal of Environmental Education, v. 30, n. 1, p. 11-19, 1998.

SAARINEN, T. F. Perception of the drought hazard on the great plains. Chicago: 
University of Arizona, 1966 (Research paper, n. 106).

SAQUET, M. A. Os tempos e os territórios da colonização italiana: o desenvolvimento econômico na Colônia Silveira Martins (RS). Porto Alegre: Edições EST, 2003.

SLOVIC, P. The perception of risk. London: Earthscan, 2000.

TUAN, Y.-F. Topofilia: um estudo da percepção, atitudes e valores do meio ambiente. Trad. Lívia de Oliveira. São Paulo: Difel, 1980.

Espaço e lugar: a perspectiva da experiência. Trad. Lívia de Oliveira. São Paulo: Difel, 1983.
Paisagens do medo. Trad. Lívia de Oliveira. São Paulo: Ed. Unesp, 2005.

VOSS, P. R. Demography as a spatial social science. Population Research and Policy Review, v. 26, n. 5-6, p. 457-476, 2007.

WILDAVSKY, A.; DAKE, K. Theories of risk perception: who fears what and why? Daedalus, v. 119, n. 4, p. 41-60, 1994.

WISNER, B.; BLAIKIE, P. M.; CANNON, T.; DAVIS, I. At risk: natural hazards, people's vulnerability, and disasters. 2 ed. London: Routledge, 2004.

\section{Resumen}

Percepción de los peligros ambientales urbanos y los efectos de lugar en la relación población-ambiente

Los estudios ambientales se enfrentan, desde su aparición, al fantasma de la falacia ecológica. Especialmente en el ámbito de las ciencias humanas, siempre se prestó una atención redoblada a todo lo referente a cualquier forma de determinismo geográfico o interpretación que sometiera la comprensión de la sociedad a la lógica de la naturaleza. En los estudios de Población y Ambiente (P-A), esta preocupación estuvo siempre presente, no siendo raro el debate sobre la falacia ecológica, sus riesgos y la búsqueda de formas de eliminarla del objeto de los análisis. No obstante, con el aumento del interés por parte de las ciencias humanas hacia el espacio en las últimas décadas, la importancia de la espacialidad, y la continua incorporación de su dimensión en los análisis, han renovado esta preocupación, pero esta vez en un nuevo contexto sociocultural. La idea de efectos de lugar gana relevancia a medida que se reconoce, en dirección opuesta a la globalización, el refuerzo de factores regionales y locales en la determinación y mediación de problemáticas ambientales, que afectan a poblaciones y lugares de manera específica, y no de forma indiscriminada por el espacio. En ese contexto, el debate metodológico necesita prestar atención a la forma en la que el espacio entra en la ecuación P-A, sin desconsiderar los debates previos o los nuevos esquemas socioespaciales contemporáneos. Estas cuestiones se presentaron como algo relevante en la investigación desarrollada sobre la percepción de los peligros y la vulnerabilidad en las Regiones Metropolitanas de Campinas y de la Baixada Santista, en el Estado de Sao Paulo. Utilizando datos de una investigación por domicilios desarrollada en 2007 (Proyecto Vulnerabilidad), procuramos ir más allá de las variables que habitualmente nos ayudan a reflexionar sobre las cuestiones relacionadas con la situación de vida (renta, escolaridad, ciclo vital), intentando entenderlas en escalas espaciales diferenciadas, incorporando los efectos de lugar como algo fundamental para comprender la percepción de los peligros urbanos en la relación población-espacio-ambiente.

Palabras-clave: Riesgos. Espacio. Migración. Metodología. Población. Ambiente. 


\begin{abstract}
Perception of urban environmental threats and place effects on the population-environment relationship
\end{abstract}

Since their beginning, environmental studies have faced the threat of the ecological fallacy. Particularly within the human sciences domain, there has always been special attention to any form of geographical determinism or interpretation that could link society's understanding to nature's rationale. Regarding Population and Environment (P-E) studies, the concern has always been present, and not rarely with debate over the ecological fallacy, its risks and ways to eradicate it from the scope of analyses. However, in past decades, with the growing interest of human sciences on space, the importance of spatiality and the continuous amalgamation of its dimension in analyses have renewed this concern, now within a new sociocultural context. The effects of space have taken a new dimension, as we recognize, against the globalization trend, the strength of regional and local factors upon the determination and mediation of environmental issues that affect populations and places in a specific, but not in an indiscriminate way for space. Based on this, the methodological discussion has to consider how space influences the P-E equation, taking into consideration previous debates and the new contemporaneous sociospatial arrangements. These issues were relevant in the investigation over the perception of the dangers and vulnerability in the Metropolitan Regions of Campinas and Baixada Santista, in the State of São Paulo. Using data from a 2007 household survey (Vulnerability Project), we aimed to reach beyond the variables commonly used to assess living conditions (income, education, vital cycle), and we attempted to understand the variables according to differentiated spatial scales, considering the effects of space as critical for the perception of urban threats within the population-space-environment relationship.

Keywords: Risks. Space. Migration. Methodology. Population. Environment. 